NATIONAL LABORATORY

\title{
Methodology for Mechanical Property Testing on Fuel Cladding Using an Expanded Plug Wedge Test
}

\section{August 2013}

Prepared by

Jy-An John Wang

Hao Jiang

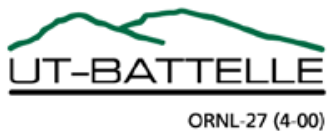




\title{
DOCUMENT AVAILABILITY
}

Reports produced after January 1, 1996, are generally available free via the U.S. Department of Energy (DOE) Information Bridge.

Web site http://www.osti.gov/bridge

Reports produced before January 1, 1996, may be purchased by members of the public from the following source.

\author{
National Technical Information Service \\ 5285 Port Royal Road \\ Springfield, VA 22161 \\ Telephone 703-605-6000 (1-800-553-6847) \\ TDD 703-487-4639 \\ Fax 703-605-6900 \\ E-mail info@ntis.gov \\ Web site http://www.ntis.gov/support/ordernowabout.htm
}

Reports are available to DOE employees, DOE contractors, Energy Technology Data Exchange (ETDE) representatives, and International Nuclear Information System (INIS) representatives from the following source.

Office of Scientific and Technical Information

P.O. Box 62

Oak Ridge, TN 37831

Telephone 865-576-8401

Fax 865-576-5728

E-mail reports@osti.gov

Web site http://www.osti.gov/contact.html

This report was prepared as an account of work sponsored by an agency of the United States Government. Neither the United States Government nor any agency thereof, nor any of their employees, makes any warranty, express or implied, or assumes any legal liability or responsibility for the accuracy, completeness, or usefulness of any information, apparatus, product, or process disclosed, or represents that its use would not infringe privately owned rights. Reference herein to any specific commercial product, process, or service by trade name, trademark, manufacturer, or otherwise, does not necessarily constitute or imply its endorsement, recommendation, or favoring by the United States Government or any agency thereof. The views and opinions of authors expressed herein do not necessarily state or reflect those of the United States Government or any agency thereof. 
Materials Science and Technology Division Oak Ridge National Laboratory

\title{
METHODOLOGY FOR MECHANICAL PROPERTY TESTING ON FUEL CLADDING USING AN EXPANDED PLUG WEDGE TEST
}

\author{
Jy-An John Wang
}

Hao Jiang

Date Published: August 2013

Prepared by

OAK RIDGE NATIONAL LABORATORY

Oak Ridge, Tennessee 37831-6283

managed by

UT-BATTELLE, LLC

for the

U.S. DEPARTMENT OF ENERGY

under contract DE-AC05-00OR22725 



\section{CONTENTS}

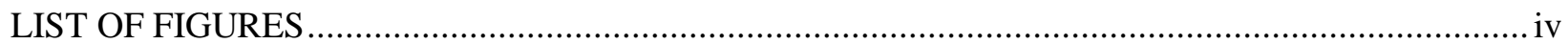

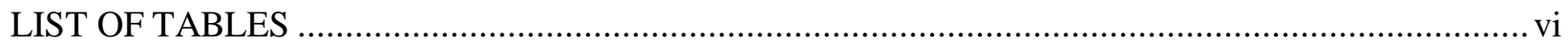

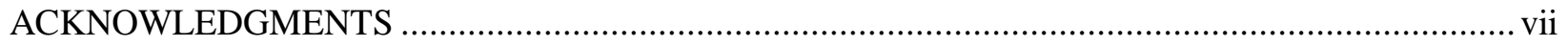

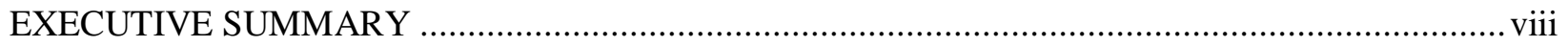

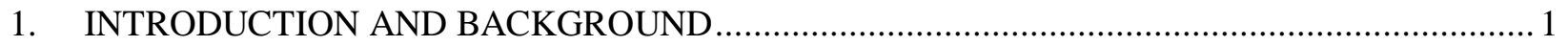

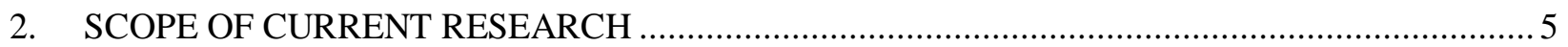

3. EVALUATION OF CURRENT EXPANDED PLUG METHOD USING FEA............................ 6

3.1 FEA OF ROOM-TEMPERATURE RING EXPANSION CLAD TESTING ....................... 6

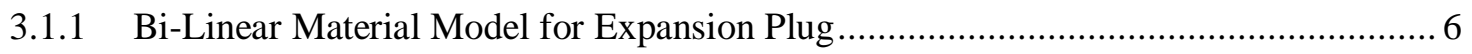

3.1.2 Hyperelastic Material Model for Expansion Plug ................................................. 9

3.2 FEA OF ELEVATED TEMPERATURE $\left(350^{\circ} \mathrm{C}\right)$ RING EXPANSION CLAD

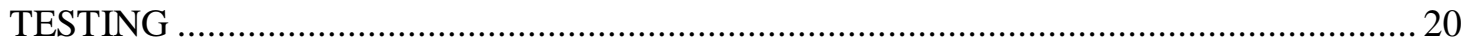

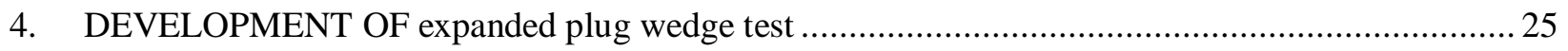

4.1 FIRST Design MODIFICATION OF THE EXPANDED PLUG TEST............................... 25

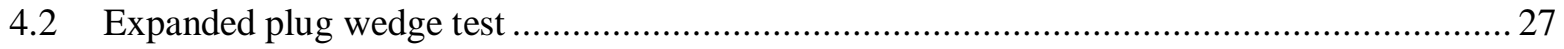

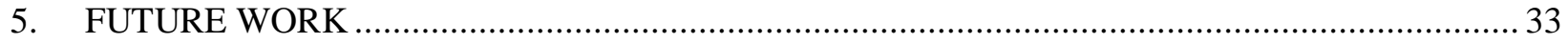

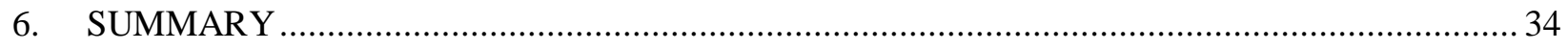

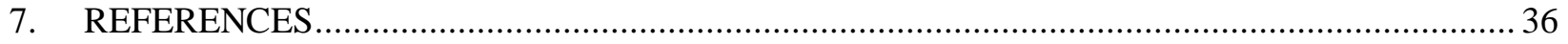




\section{LIST OF FIGURES}

Figure

Page

Fig. 1 Circumferential stress of cylinder........................................................................................ 1

Fig. 2 Schematic of expanded plug test. ..................................................................................... 2

Fig. 3 The mandrel test device (a) cladding tube with segment, (b) loading device, (c) loaded specimen with extensometer for strain measurement. .......................................................... 3

Fig. 4 A schematic for the procedure of ring tensile tests and ring specimen......................................... 4

Fig. 5 Preliminary 3D FEM model of the ring expansion clad testing system. .................................... 6

Fig. 6 Modified 3D FEM model of the ring expansion clad testing system. .................................... 7

Fig. 7 Nonuniform stress distribution in the clad for FEM with the bi-linear material model of

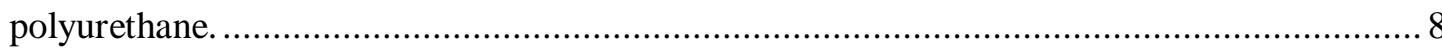

Fig. 8 Nonuniform contact stress in the clad for FEM with the bi-linear material model of

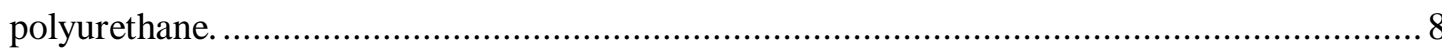

Fig. 9 Shear stress distribution in the clad for FEM with bi-linear material model of polyurethane. .......... 9

Fig. 10 Stress distribution at the mid-section of the clad for FEM with bi-linear material model of

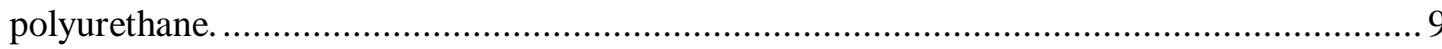

Fig. 11 3D FEM model of ring expansion clad test system with hyperelastic material model for

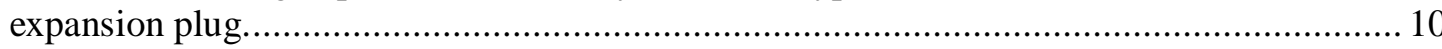

Fig. 12 A typical final data set for input into a curve fitter.............................................................. 10

Fig. 13 Hyperelastic material properties testing for polyurethane plug................................................ 11

Fig. 14 Hyperelastic material property test data for polyurethane. .................................................... 12

Fig. 15 A tensile stress-strain curve of unirradiated Zr-4 ............................................................. 12

Fig. 16 Non-uniform stress distribution in the clad for FEM with hyperelsasitc material model of

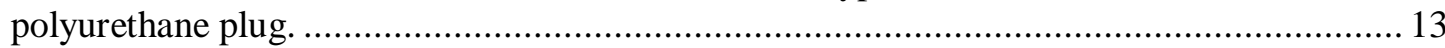

Fig. 17 Nonuniform contact stress distribution in the clad for FEM with hyperelastic material model of polyurethane plug. ........................................................................................ 14

Fig. 18 Nonuniform radial dilatation in the clad for FEM with hyperelastic material model of

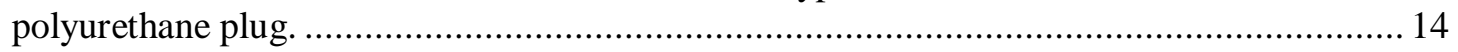

Fig. 19 Tested unirradiated Zr-4 ring specimen at room temperature. .............................................. 15

Fig. 20 Test setup for ring tensile testing using proximity transducers. .......................................... 15

Fig. 21 The resultant axial stress in the middle section of the clad. ................................................. 16

Fig. 22 Sketch of stress comparison between pressured cylinder and expansion plug test. ..................... 17

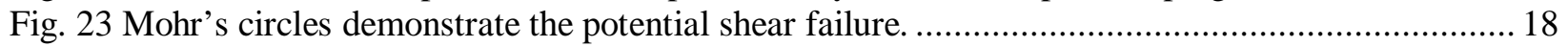

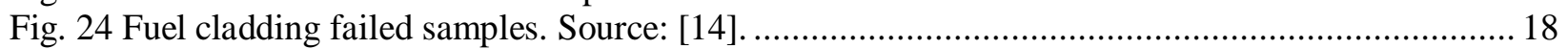

Fig. 25 Typical axial splitting in high-burnup clad. Source: [15]. .................................................. 18

Fig. 26 Resultant stress distribution in current expansion plug testing system................................... 20

Fig. 27 3D FEM model of ring expansion clad test system with copper plug at elevated temperature...... 20

Fig. 28 Copper plug material property test data at $350^{\circ} \mathrm{C}$. ............................................................ 21

Fig. 29 Nonuniform stress distribution in SRA Zr-4 clad for FEM with deformation plastic material

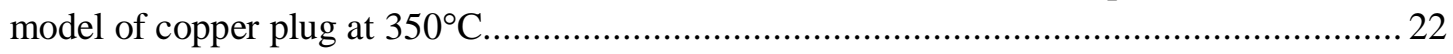

Fig. 30 Nonuniform contact stress distribution in SRA Zr-4 clad for FEM with deformation plastic

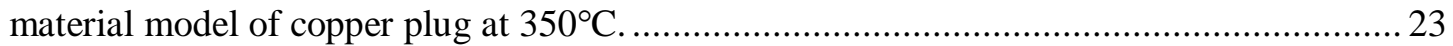

Fig. 31 Nonuniform radial dilatation in SRA Zr-4 clad for FEM with deformation plastic material

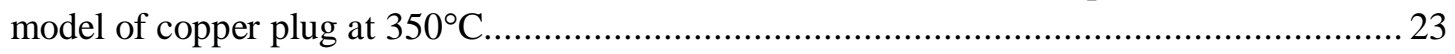

Fig. 32 Tested unirradiated ring specimen with copper plug. …....................................................... 24

Fig. 33 FEM model of first proposed design modification. .............................................................. 25

Fig. 34 Improved stress distribution in the clad for the first design modification.................................. 26

Fig. 35 Improved radial dilatation distribution at the gage section for the first design modification......... 27 
Fig. 36 Axial stress and shear stress distribution in the clad for the first design modification................ 27

Fig. 37 FEM model of expanded plug wedge test design. .............................................................. 28

Fig. 38 Uniform stress distribution in the clad for expanded plug wedge test...................................... 29

Fig. 39 Uniform radial dilatation distribution at the gage section for expanded plug wedge test.............. 30

Fig. 40 Axial stress and shear stress distribution in the clad for expanded plug wedge test..................... 30

Fig. 41 Ring load determined by total load and plug load in expanded plug wedge test design................ 31

Fig. 42 Ring load-radial strain data from the ring test converted into material stress-strain curve for the modified expanded plug test design with wedge insertsexpanded plug wedge test.......... 32 


\section{LIST OF TABLES}

\section{Table}

Page

Table 1. Material properties of components with bi-linear material model of expansion plug ..... 7 Table 2. Material properties of components with hyperelastic material model of expansion plugError! Bookmark not def Table 3. Radial dilatation of unirradiated Zr-4 specimen comparison between test and FEA..... 15

Table 4. True stress range in unirradiated Zr-4 cladding from FEA results ......................................... 16

Table 5. Summary of round-robin test results for Zr-4 clad from Ref. [14] ......................................... 19

Table 6. Summary of component material properties for FEA at elevated temperature .......................... 21

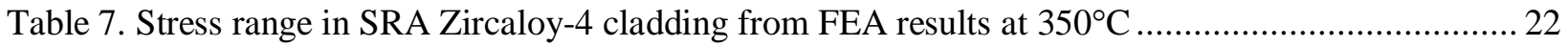

Table 8. Component material properties of the first design modification ............................................. 26

Table 9. Component material properties of expanded plug wedge test ............................................... 28 


\section{ACKNOWLEDGMENTS}

This research was sponsored by the Fuel Qualification Program of Department of Energy and was carried out at Oak Ridge National Laboratory under contract DE-AC05-00OR22725 with UT-Battelle, LLC.

The authors would like to thank Program Managers, Bruce Bevard and Don Spellman, for providing guidance and support to this project, James Hemrick for providing test data for hyperelastic material modeling, and Amy Harkey for editing and reviewing the report. 


\section{EXECUTIVE SUMMARY}

To determine the tensile properties of irradiated fuel cladding in a hot cell, a simple test was developed at ORNL and is described fully in US Patent Application 20060070455, "Expanded plug method for developing circumferential mechanical properties of tubular materials." This method is designed for testing fuel rod cladding ductility in a hot cell utilizing an expandable plug to stretch a small ring of irradiated cladding material. The specimen strain is determined using the measured diametrical expansion of the ring. This method removes many complexities associated with specimen preparation and testing. The advantages are the simplicity of measuring the test component assembly in the hot cell and the direct measurement of specimen strain. It was also found that cladding strength could be determined from the test results.

The basic approach of this test method is to apply an axial compressive load to a cylindrical plug of polyurethane (or other materials) fitted inside a short ring of the test material to achieve radial expansion of the specimen. The diameter increase of the specimen is used to calculate the circumferential strain accrued during the test. The other two basic measurements are total applied load and amount of plug compression (extension). A simple procedure is used to convert the load-circumferential strain data from the ring tests into material pseudo-stress-strain curves.

However, several deficiencies exist in this expanded-plug loading ring test, which will impact accuracy of test results and introduce potential shear failure of the specimen due to inherited large axial compressive stress from the expansion plug test. First of all, the highly non-uniform stress and strain distribution resulted in the gage section of the clad. To ensure reliable testing and test repeatability, the potential for highly non-uniform stress distribution or displacement/strain deformation has to be eliminated at the gage section of the specimen. Second, significant compressive stresses were induced by clad bending deformation due to a clad bulging effect (or the barreling effect). The barreling effect caused very large localized shear stress in the clad and left testing material at a high risk of shear failure. The above combined effects will result in highly non-conservative predictions both in strength and ductility of the tested clad, and the associated mechanical properties as well.

To overcome/mitigate the mentioned deficiencies associated with the current expansion plug test, systematic studies have been conducted. Through detailed parameter investigation on specific geometry designs, careful filtering of material for the expansion plug, as well as adding newly designed parts to the testing system, a method to reconcile the potential non-conservatism embedded in the expansion plug test system has been discovered. An expanded plug wedge test has been developed based on the method.

In order to closely resemble thin-wall theory, a general procedure was also developed to estimate the hoop stress $\sigma_{\theta}$ in the tested ring specimen. A scaling factor, $\chi$-factor, is developed to convert the ring load $\mathrm{F}_{\text {ring }}$ into hoop stress $\sigma_{\theta}$, and written as $\sigma_{\theta}=\chi \frac{F_{\text {ring }}}{t l}$. The generated stress-strain curve agrees well with the associated tensile test data in both the elastic and plastic regions. 



\section{INTRODUCTION AND BACKGROUND}

Fuel and clad must be examined to verify the performance of fuel rods and to produce data that can be used for fuel qualification. One of the essential examinations is the mechanical properties test. In a hot-cell environment, conventional tensile testing might not be convenient due to complexities associated with specimen preparation and testing. Hendrich et al. [1] invented an expanded plug method and applied it in Fissile Materials Disposition Program (FMDP) to do Post Irradiation Examination (PIE) for the performance of the fuel rods contained in the mixed oxide (MOX) lead test assemblies. The advantages of the method described in the patent application are simplicity of use of the test component assembly in the hot cell and the direct measurement of specimen strain. It was also found that cladding strength could be determined from the test results.

It is important to understand the thin-walled pressurized cylinder model on which the expanded plug method was based. If the cylinder walls are thin and the ratio of the thickness to the internal diameter is less than about $1 / 20$, then it can be assumed to be a thin-walled vessel [1] [2] [3]. The three principal stresses in the shell are circumferential or hoop stress, longitudinal stress, and radial stress. For the thinwalled cylinder it may be assumed that the hoop and longitudinal stresses are constant across the thickness. The radial stress is small and can be neglected. As shown in Fig. 1, the hoop stress can be described as

$$
\sigma_{\theta}=\frac{F}{t l}
$$

where $F$ is the force exerted circumferentially on an area of the cylinder wall that has a radial thickness $t$ and an axial length $l$.

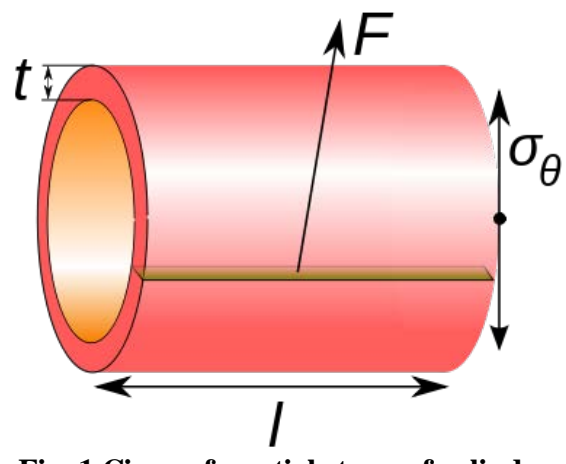

Fig. 1 Circumferential stress of cylinder.

Using the Young-Laplace equation, the hoop stress created by an internal pressure on a thin-walled cylindrical pressure vessel can be estimated as

$$
\sigma_{\theta}=\frac{P r}{t}
$$

where $P$ is the internal pressure, $t$ is the wall thickness, and $r$ is the inside radius of the cylinder.

When the cylinder to be studied has an $r / t$ ratio of less than 10 , the thin-walled cylinder equations are no longer valid. Between inside and outside surfaces, stresses can vary significantly and shear stress through 
the cross section can no longer be neglected. Estimation of stress and strain becomes much more complicated.

A simple test was developed at ORNL and is fully described in US Patent Application 20060070455, "Expanded plug method for developing circumferential mechanical properties of tubular materials" [4], as shown in Fig. 2. This method is designed for testing fuel rod cladding ductility in a hot-cell utilizing an expandable plug to stretch a small ring of the irradiated cladding material. The basic approach of this test method is to apply an axial compressive load to a cylindrical plug of polyurethane (or other materials) fitted inside a short ring of the test material to achieve radial expansion of the specimen. Three major measurements are made, including total applied load, extension of plug compression, and radial expansion of the specimen. The radial expansion of the specimen is used to calculate the circumferential strain accrued during the test.

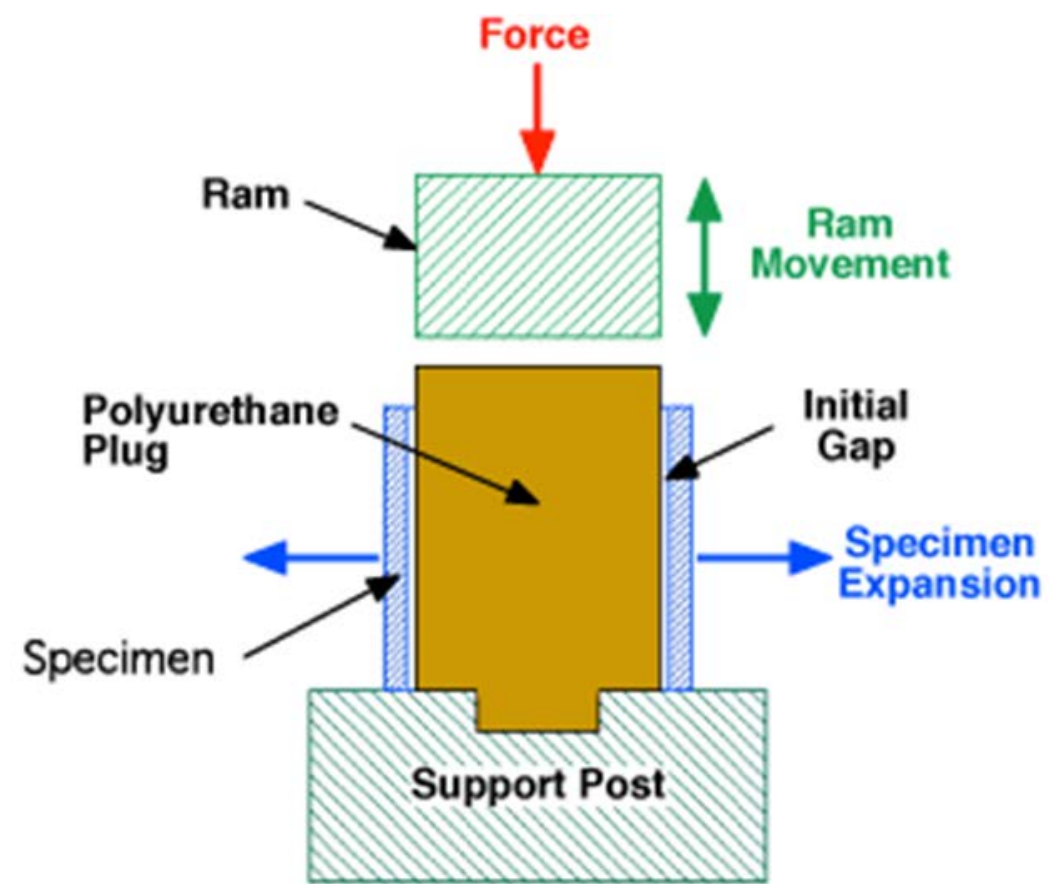

Fig. 2 Schematic of expanded plug test.

A general procedure has been developed to determine the circumferential stress $\left(\sigma_{\mathrm{CIR}}\right)$ in the expanded ring specimen [14]. The circumferential stress is calculated using a scaling parameter called a $\Gamma$-factor $(\Gamma)$, the load $(P)$, and the specimen dimensions as shown below.

$$
\sigma_{C I R}=\frac{\Gamma P}{t l}
$$

where

$$
\Gamma=\frac{\sigma_{\text {Yield }}}{P_{\text {Yield }}} l l
$$

and,

$\sigma_{\text {Yield }}=$ yield stress of a quality assured material determined using a standard tensile test,

$P_{\text {Yield }}=$ load at $0.2 \%$ plastic strain offset measured using a ring specimen of the above QA'd material, 


$$
\begin{aligned}
& t=\text { ring specimen thickness, } \\
& l=\text { ring specimen axial length. }
\end{aligned}
$$

Therefore, the load and radial expansion data from the ring tests can be converted into material pseudostress-strain curves to examine mechanical properties, such as Young's modulus, yield strength, and strain-hardening characteristics.

In nuclear engineering and design, intensive research is focusing on material characterization of fuel cladding. Among the vast literature, Nilssson et al. [6] and Kim et al. [7] did a similar investigation on fuel cladding using ring specimens. Nilsson et al. presented an assessment of the segmented expanding mandrel (SEM) test for material properties and a structural integrity assessment of nuclear fuel claddings. The test setup is shown in Fig. 3. The loading is induced by expanding segments, which are placed radially inside a cladding tube, to simulate cracked fuel that expands thermally. The test is appropriate for assessment of how defects and microstructure affect ductility.

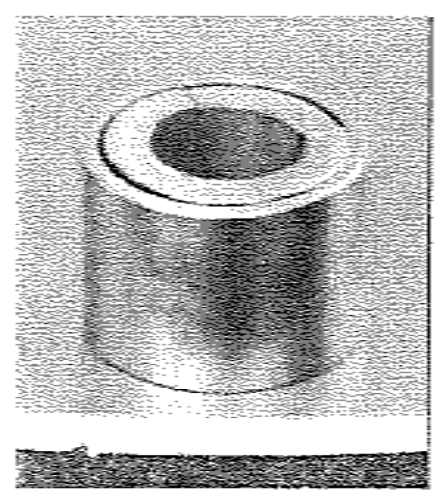

a

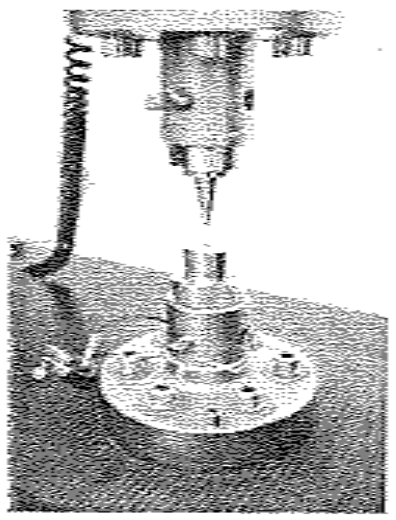

$\mathrm{b}$

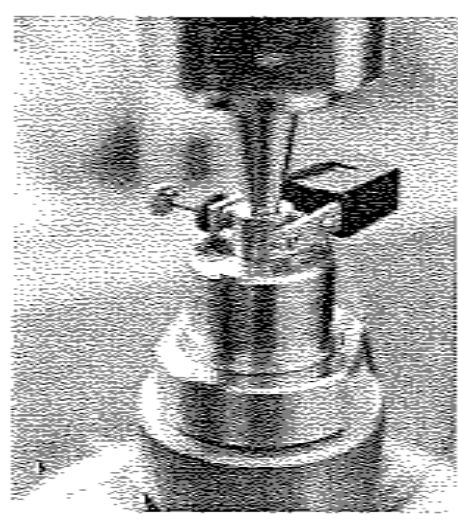

$\mathrm{C}$

Fig. 3 The mandrel test device (a) cladding tube with segment, (b) loading device, (c) loaded specimen with extensometer for strain measurement.

Kim et al. evaluated the hoop-directional mechanical properties comprising strength such as yield strength and ultimate tensile strength as well as mechanical ductility such as uniform elongation and total elongation. The ring tensile tests were performed in order to study the mechanical properties of highburnup fuel cladding under a hoop loading condition in a hot cell. The schematic test procedure and a photograph of the ring specimen are illustrated in Fig. 4. 


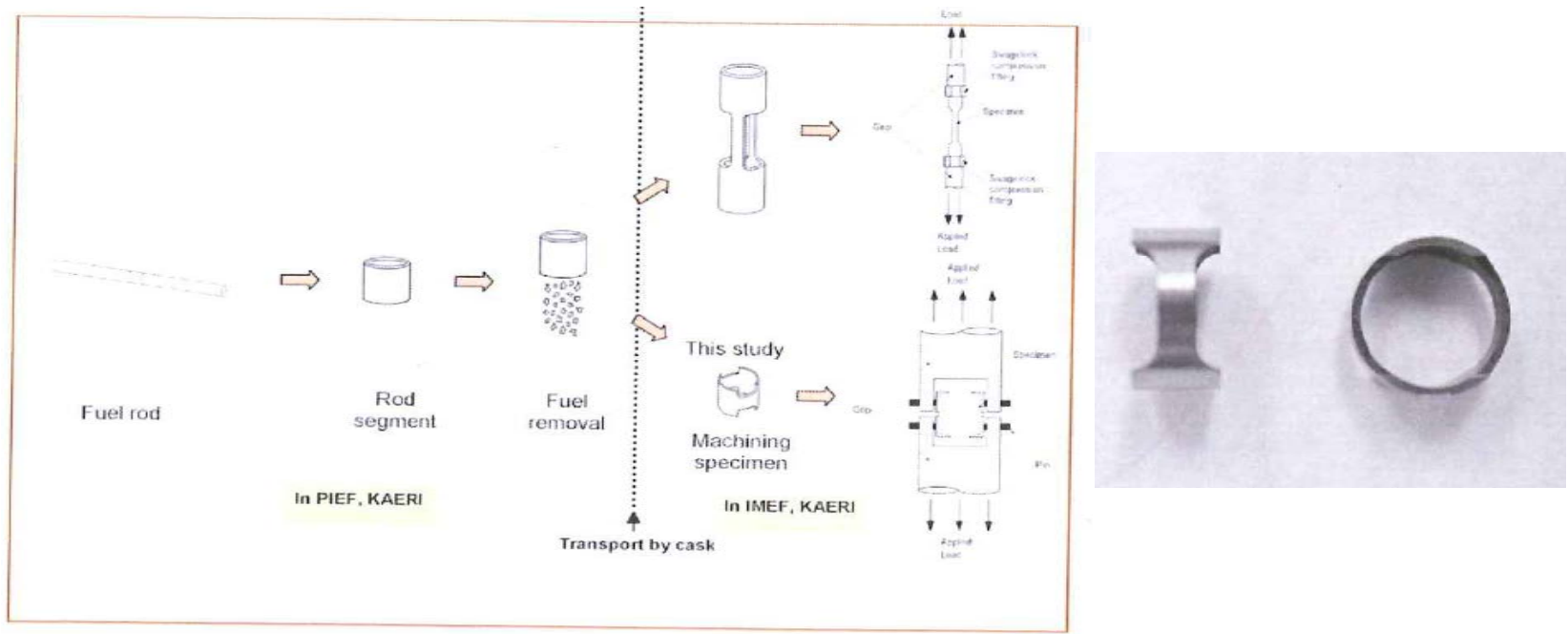

Fig. 4 A schematic for the procedure of ring tensile tests and ring specimen. 


\section{SCOPE OF CURRENT RESEARCH}

The objective of this research project is to use finite element analysis (FEA) to evaluate the patent method of the expanded plug for developing mechanical properties in fuel cladding, and based on the study to seek improvement in the expansion plug method for better performance of mechanical property testing in a hot cell. The project was divided into two stages:

1) Evaluation of the existing expanded plug method for mechanical property testing using FEA, and 2) Development of an expanded plug wedge test.

In the first stage, a series of finite element models was established to study the expanded plug testing system with various plug materials and cladding materials both at room temperature and at elevated temperature. Unconstrained compressive tests and fully constrained compressive tests were performed on polyurethane material. Hyperelastic material properties of the polyurethane plug were calibrated from both tests and provided input for the finite element model (FEM). Detailed stress and strain distribution was examined in FEA. The resultant FEM circumferential stress and radial strain of fuel cladding were validated with tensile test data and compared to mechanical properties generated from ring expansion clad testing data as well. Accomplishment in this stage demonstrated several deficiencies existing in the expanded plug method and provided important guidance for the second stage of the study.

To mitigate the deficiencies associated with the current expansion plug test, a significant effort was dedicated to seek improvement of the test design. Systematic studies have been conducted, such as a detailed parameter investigation on the geometry designs, selection of expansion plug material, as well as design of new parts for the testing system. An expanded plug wedge test has been developed to reconcile the potential nonconservatism embedded in the current expanded plug test. 


\section{EVALUATION OF CURRENT EXPANDED PLUG METHOD USING FEA}

Even though the current expanded plug method was patented back in 2006 and the method was used in testing even before that time, system simulation and evaluation using FEA has never been fully conducted due to unresolved issues with respect to numerical difficiency. In this project, a significant effort was dedicated to solve the numerical problem and establish feasible finite element models using ABAQUS codes.

\subsection{FEA OF ROOM-TEMPERATURE RING EXPANSION CLAD TESTING}

As discussed in Chapter 1, the test method was developed originally to perform room-temperature circumferential tensile testing of nuclear fuel cladding in a hot cell by radially expanding a ring specimen of the test material through axially compressing a cylindrical plug of polyurethane fitted inside the specimen.

\subsubsection{Bi-Linear Material Model for Expansion Plug}

A 3D FEM model of the ring expansion clad testing system was developed based on the test setup, as shown in Fig. 5. This first version of the model failed because it had too many contact surfaces, causing a numerical convergence problem. Learning from this preliminary FEA study, the modified 3D FEM model was established as illustrated in Fig. 6.

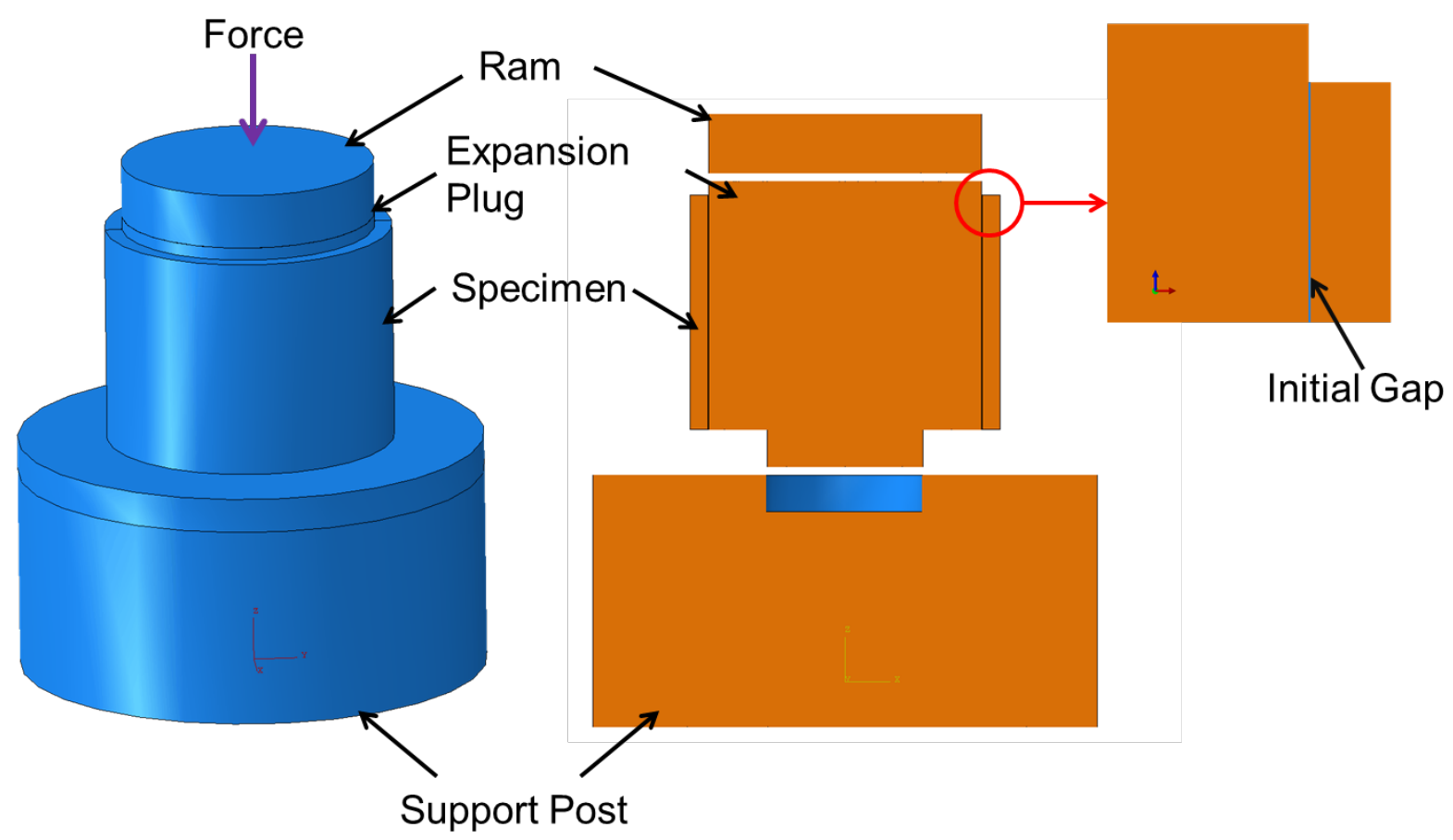

Fig. 5 Preliminary 3D FEM model of the ring expansion clad testing system. 


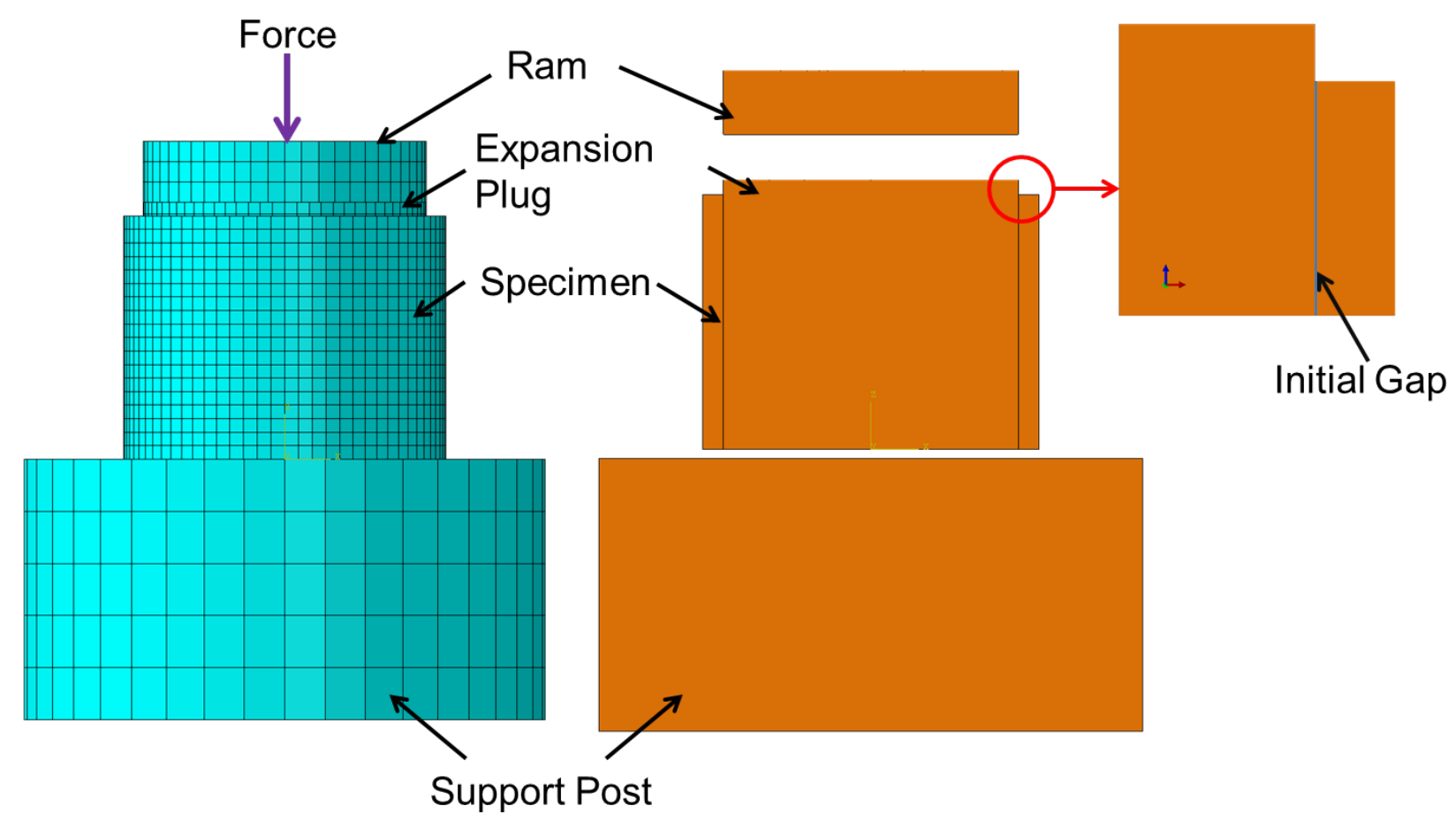

Fig. 6 Modified 3D FEM model of the ring expansion clad testing system.

In this modified model (Fig. 6), the expansion plug geometry was simplified and contact surfaces to the support were eliminated without losing generality. The slightly modified version has resolved the numerical difficulty and well represents the expanded plug method using FEA. In this model, the expansion plug used polyurethane at room temperature. The ring specimen was ferritic steel. The ram and support post utilized high strength steel as a rigid support. The material properties are listed in Table 1. The geometry of the components of the expanded plug testing system in Fig. 2 was modeled with respect to the current test setup. The ring length was simulated as 0.28 in., outer diameter (OD) of the ring was 0.37 in., and inner diameter (ID) was 0.326 in. The plug length was set to 0.296 in. and plug OD was 0.325 in. Hence the initial gap in Fig. 6 between the ring specimen and the expansion plug was 0.0005 in. Pressure load was applied to the top of the ram, while the bottom surface of the support post was constrained in six degrees of freedom (DOF). A general contact was defined as being between the outer surface of the cylindrical expansion plug and the inner surface of the ring specimen.

Table 1. Material properties of components with bi-linear material model of expansion plug

\begin{tabular}{lccc}
\hline & Young's modulus (psi) & Tensile yield stress (psi) & Poisson's ratio \\
\hline Polyurethane $^{a}$ & 69,618 & 20,015 & 0.476 \\
Ferritic steel $^{b}$ & $2.9 \times 10^{7}$ & 45,000 & 0.3 \\
High strength steel $^{c}$ & $3.0 \times 10^{7}$ & 280,000 & 0.28 \\
\hline
\end{tabular}

${ }^{a} \operatorname{Ref}[8][9]$

${ }^{b} \operatorname{Ref}[10]$

${ }^{c} \operatorname{Ref}[11]$

In Table 1, it is noticed that the hyperelastic material polyurethane was simplified as perfectly elastic plastic material (bi-linear model) per literature. Due to the lack of hyperelastic data for polyurethane at 
this first stage of the study, the FEA simulation was carried on the bi-linear material model for the expansion plug to obtain preliminary results and to guide further investigation.

Fig. 7 shows the von Mises stress distribution in the ring expansion clad testing system for the bi-linear expansion plug material model. Maximum stress occurred in the cladding for the whole system. The stress distributed nonuniformly in the clad. In this case the pressure load was 7000 psi. Contact pressure inside the inner surface of the ring specimen also shows nonuniform distribution in Fig. 8.

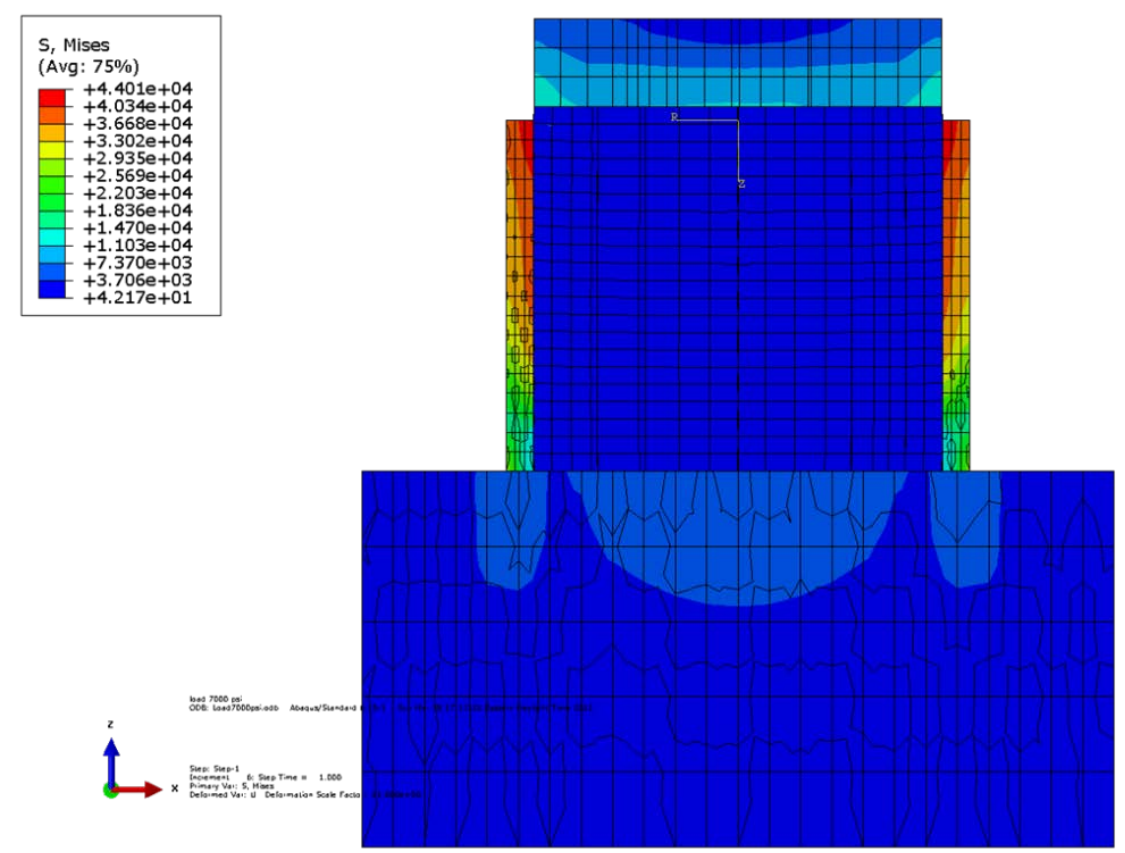

Fig. 7 Nonuniform stress distribution in the clad for FEM with the bi-linear material model of polyurethane.

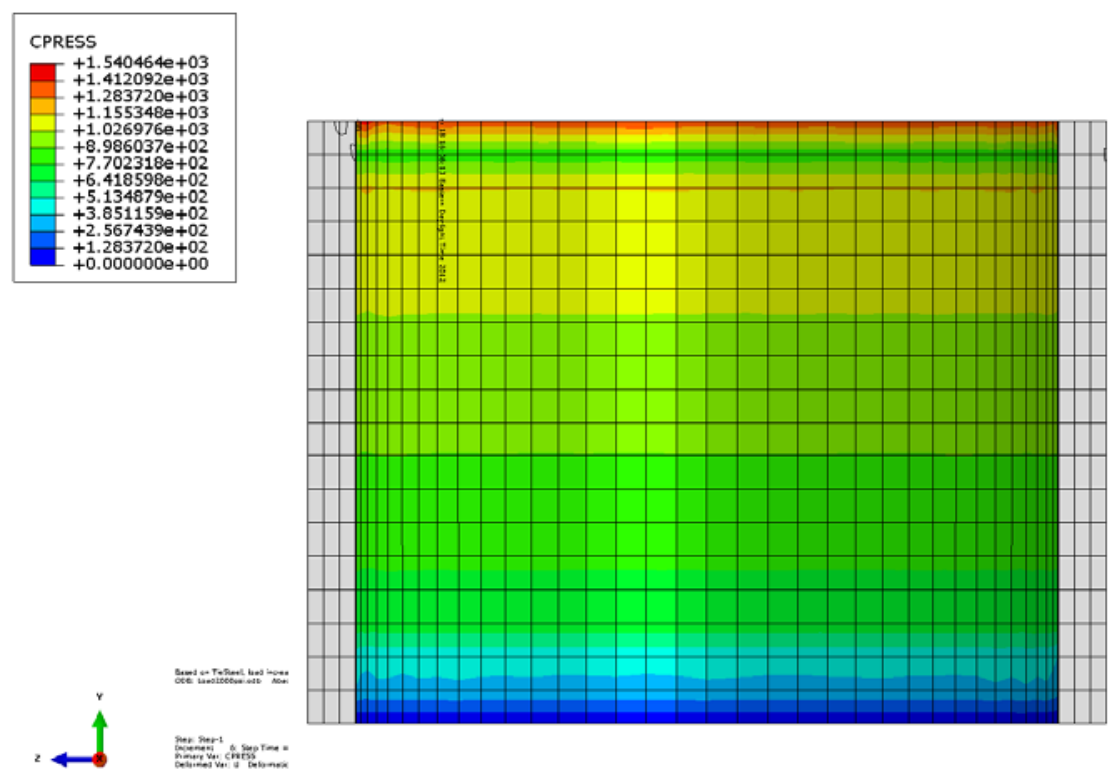

Fig. 8 Nonuniform contact stress in the clad for FEM with the bi-linear material model of polyurethane.

Fig. 9and Fig. 10 show complex stress fields existing in the cladding during a plug extension test and can no longer resemble simple pressure capsule stress distributions based on thin-walled cylinder theory. 
Shear stress $\sigma_{\mathrm{RZ}}$, radial stress $\sigma_{\mathrm{RR}}$, circumferential stress (hoop stress) $\sigma_{\mathrm{TT}}$, axial stress $\sigma_{\mathrm{ZZ}}$, as well as von Mises stress all show gradient distributions through a cross section of the ring specimen. All these preliminary results indicate that the circumferential tensile properties test of the ring specimen using the current ORNL patented expanded plug method is much more complicated than the thin-walled cylinder and needs thorough investigation, especially for the hyperelastic material model of the polyurethane plug.

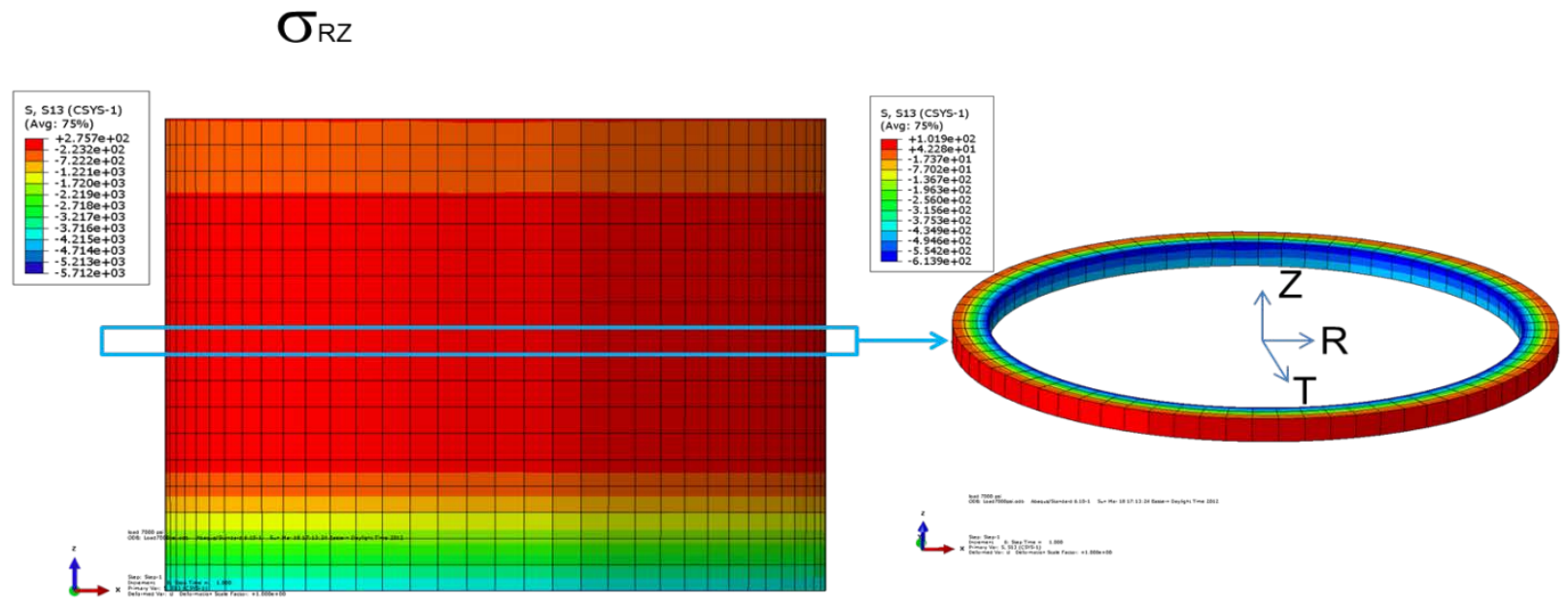

Fig. 9 Shear stress distribution in the clad for FEM with bi-linear material model of polyurethane.
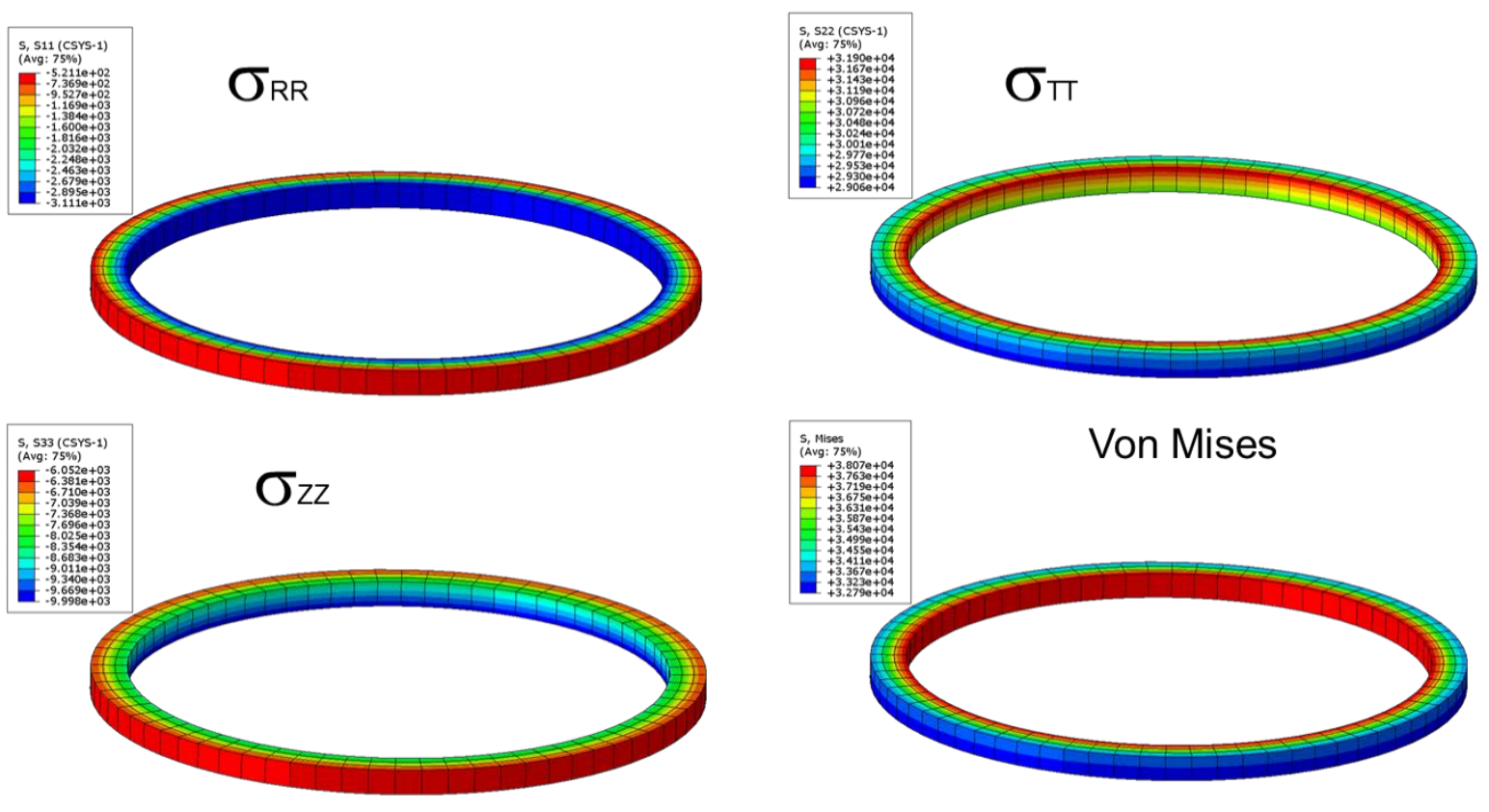

1.

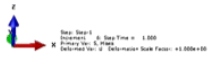

Fig. 10 Stress distribution at the mid-section of the clad for FEM with bi-linear material model of polyurethane.

\subsubsection{Hyperelastic Material Model for Expansion Plug}

The modified 3D FEM model of the ring expansion clad testing system (Fig. 6) was followed in this further study of the hyperelastic material model for a polyurethane plug, as shown in Fig. 11. To permit 
direct comparison to existing test data and validate simulation results, the material of the ring specimen was a zirconium alloy Zr-4. Polyurethane material was used for the expansion plug. High strength steel was still used for the ram and the support post. The geometry of the components was exactly the same as shown in Fig. 6. The boundary condition was still fixed at 6 DOF at the bottom surface of the support post. The load was $1040 \mathrm{lbf}$ for testing an unirradiated Zr-4 ring specimen at room temperature.

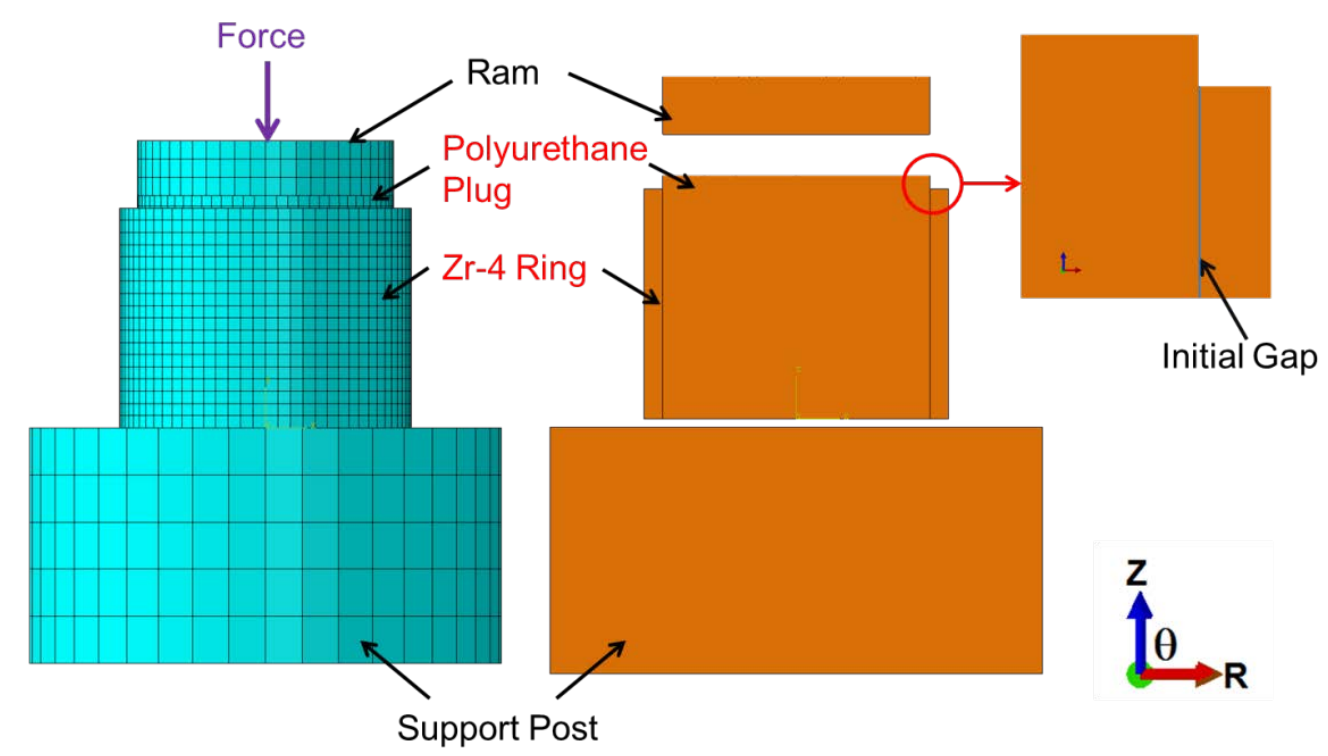

Fig. 11 3D FEM model of ring expansion clad test system with hyperelastic material model for expansion plug.

For hyperelastic characterization of the polyurethane material, the hyperelastic material model in ABAQUS was used to simulate the material behavior of polyurethane during the ring expansion clad testing at room temperature. Fig. 12 shows an example of a typical final test data set for input into a curve fitter [12]. The objective of the testing is to define and to satisfy the input requirements of the mathematical material models that exist in the structural, nonlinear FEA model.

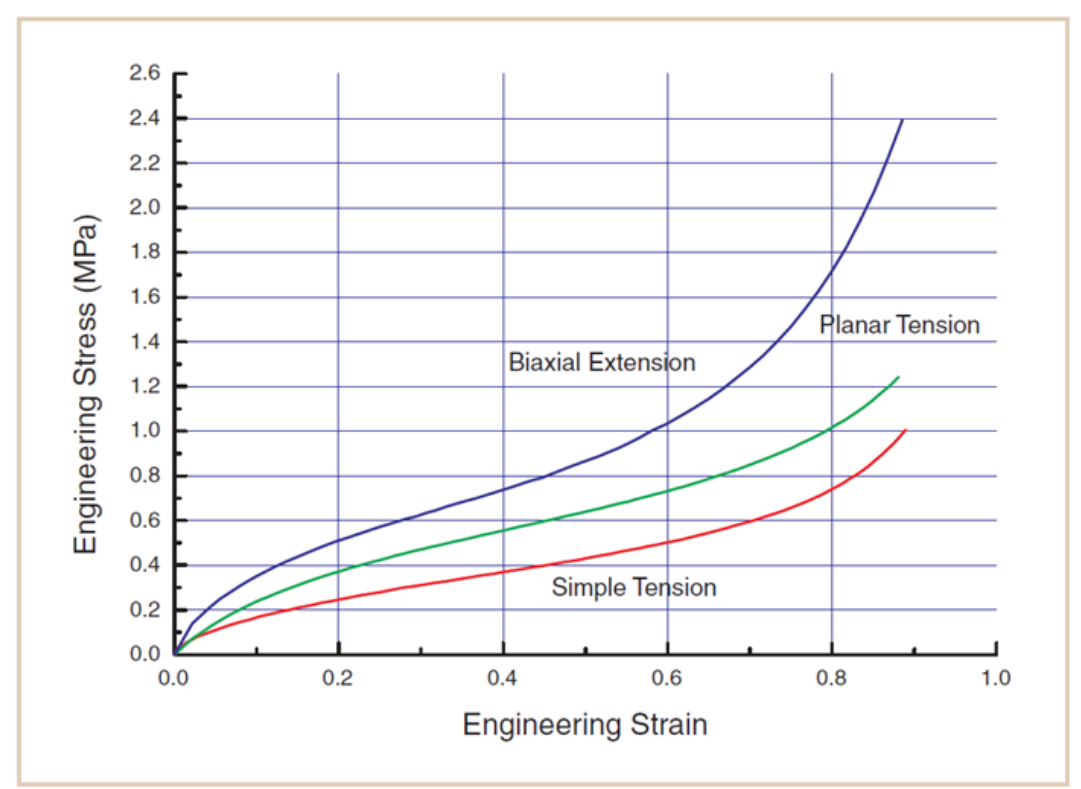

Fig. 12 A typical final data set for input into a curve fitter. 
Two tests were identified for the test data set to generate hyperelastic material model parameters for the polyurethane plug: an unconstrained compressive test (or uniaxial compressive test) and a fully constrained compressive test (or volumetric test), shown in Fig. 13(a) and (b) respectively. The uniaxial compression experiment is a popular test for hyperelastic material. When testing for analysis, pure states of strain are desired, and this is especially difficult to achieve experimentally in compression due to friction. So lubrication between the specimen and the platen will be needed to reduce shear strain induced by friction. Volumetric compression is an experiment where the compressibility of the material is examined. In this experiment, a cylindrical specimen is constrained in a fixture and compressed [Fig. 13(b)]. In these tests, six polyurethane specimens with diameter 0.358 in. and length 0.295 in. were prepared: three specimens for uniaxial compressive testing, and three for volumetric testing.

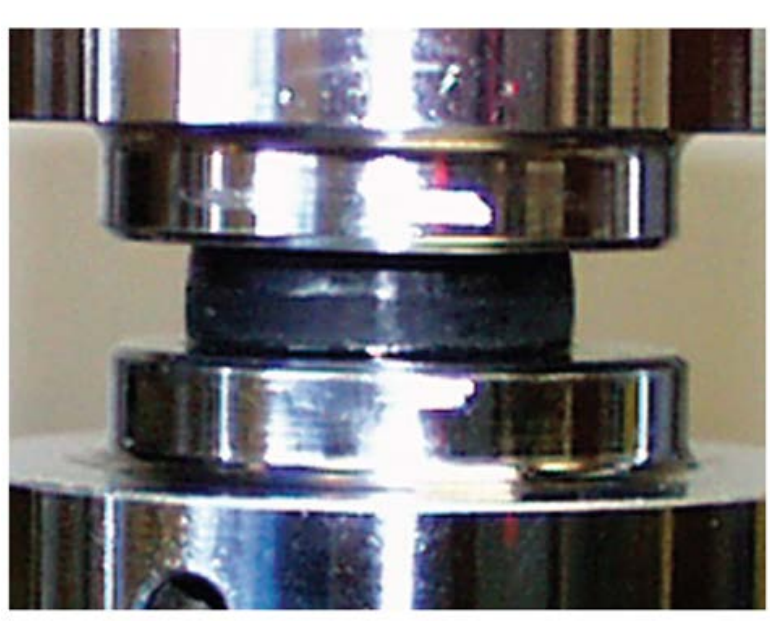

(a) Uniaxial compressive test

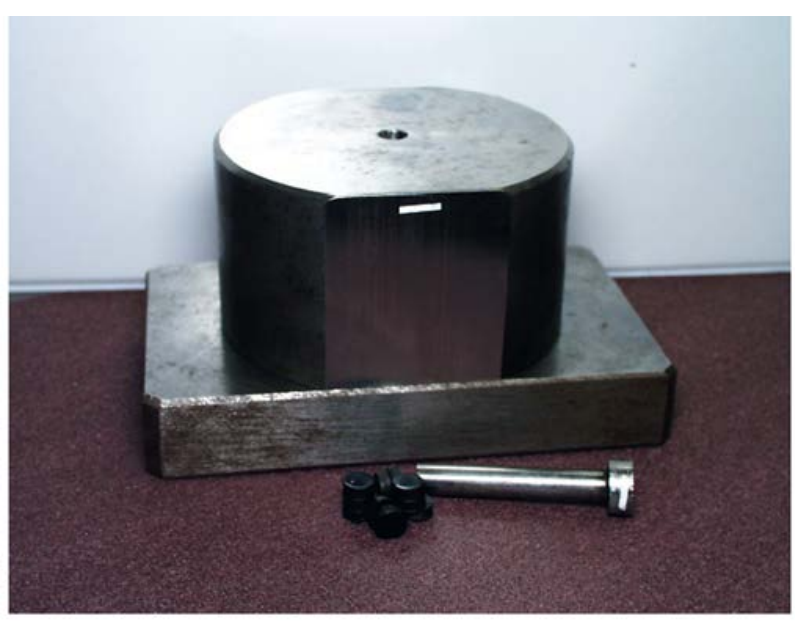

(b) Volumetric test

Fig. 13 Hyperelastic material properties testing for polyurethane plug.

Uniaxial compressive test data and volumetric test data are shown by the blue line in Fig. 14. The test data were evaluated in ABAQUS/CAE using the hyperelastic model to determine the optional strain energy potential and to calibrate coefficients as an input parameter in the FEA model. Fig. 14 reveals that strain energy potential form of Yeoh [13] as a hyperelastic material model is a good match with both unconstrained compressive test data and fully constrained test data. The three coefficients C10, C20, and C30 of deviatoric behavior for the Yeoh form, calibrated from unconstrained uniaxial test data [Fig. 14(a)], are 1319, -708, and 699, respectively. The compressibility of polyurethane needs to be specified. If the material is considered incompressible, the three coefficients of compressibility D1, D2, and D3 can be defined as zeros. However, polyurethane exhibits nearly incompressible material behavior, so the coefficients D1, D2, and D3 are computed from volumetric test data [Fig. 14(b)] as $1.296 \times 10^{-5}, 5.648 \times 10^{-}$ ${ }^{7}$, and $-4.362 \times 10^{-8}$, respectively. The other strain energy potential of the Marlow form basically just uses unconstrained and constrained test data directly. So in the following study, both the Yeoh and the Marlow forms were utilized in the FEA model as hyperelastic material behavior for the polyurethane plug. 


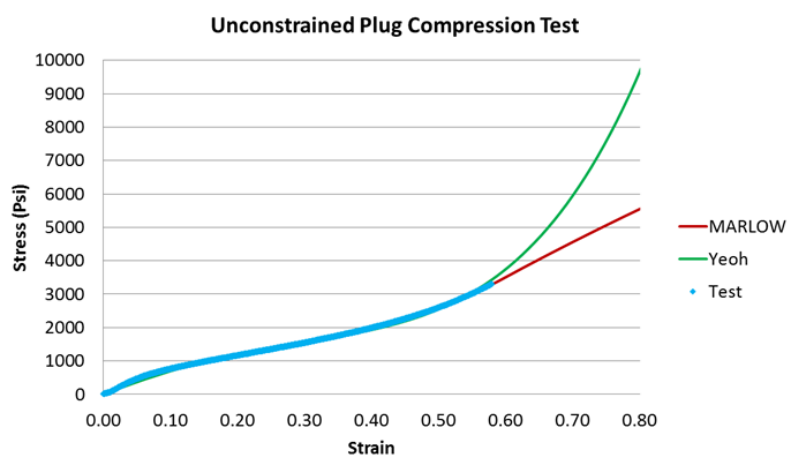

(a)

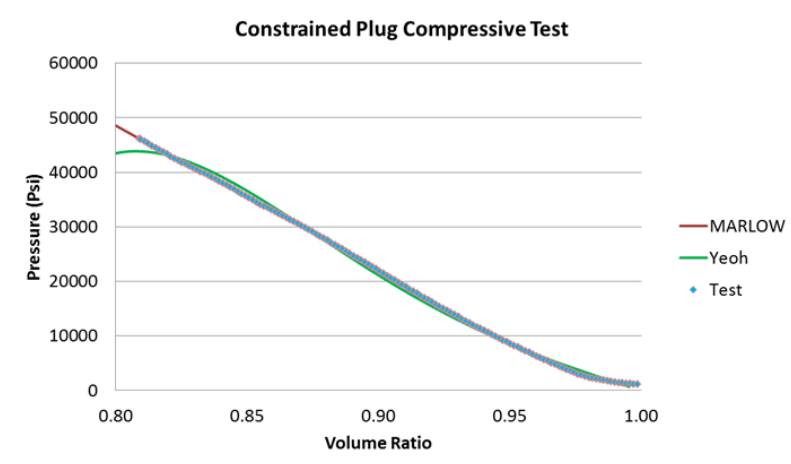

(b)

Fig. 14 Hyperelastic material property test data for polyurethane.

The material properties of components simulated in the system model in Fig. 11 are listed in Table 2. Unirriadiated Zr-4 material properties are cited from Ref. [5]. Fig. 15 illustrates the tensile stress-strain curve for unirradiated Zr-4 cladding generated from data in Ref. [5]. The transverse ultimate strength of unirradiated Zr-4 cladding is up to $74.6 \mathrm{ksi}$. Strain hardening data was generated on the basis of tensile test data and provided to the FEA model as plastic material behavior of $\mathrm{Zr}-4$ during the ring expansion test simulation.

Table 2. Material properties of components with hyperelastic material model of expansion plug

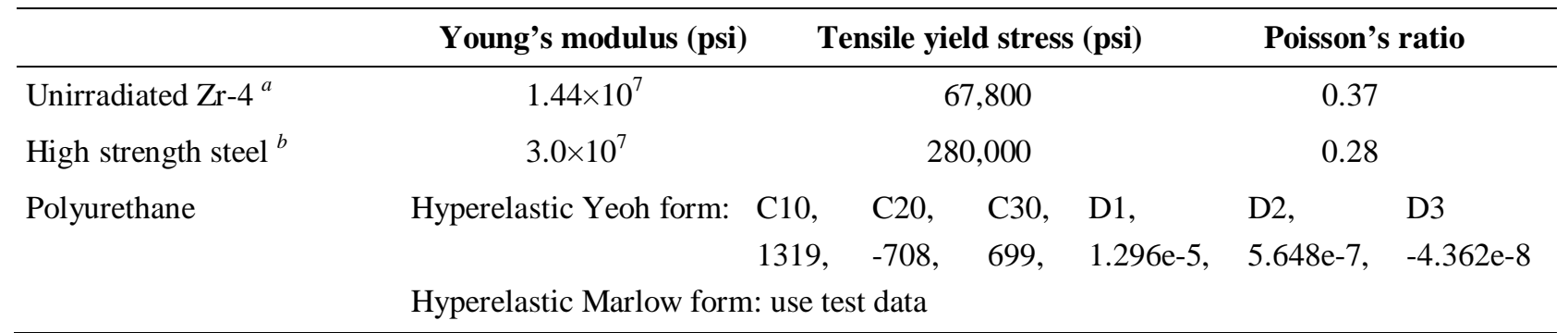

\footnotetext{
${ }^{a}$ Ref. [5]

${ }^{b}$ Ref. [11].
}

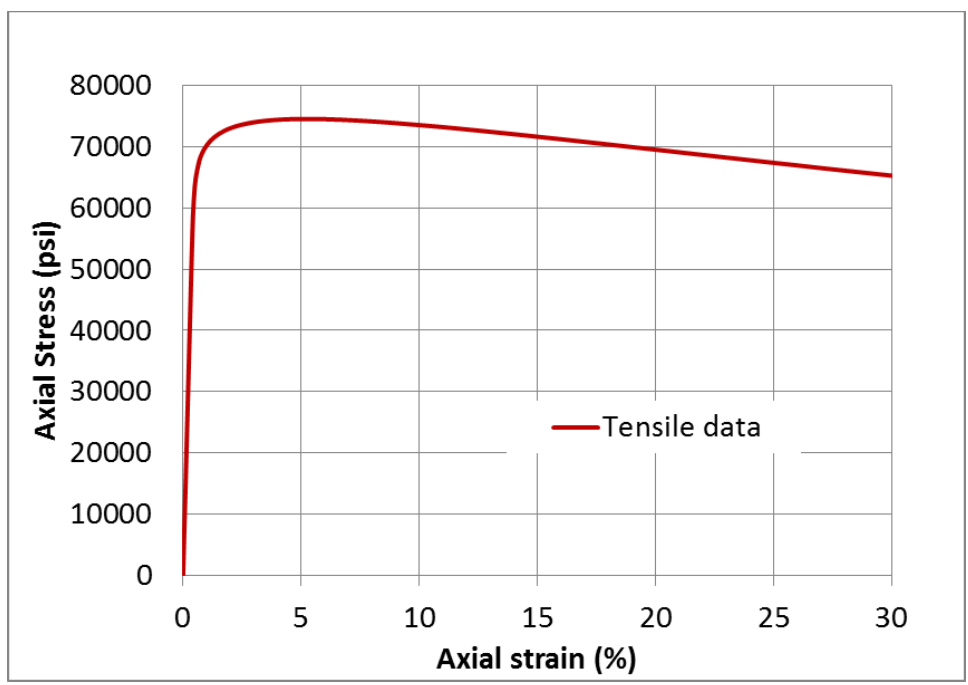

Fig. 15 A tensile stress-strain curve of unirradiated Zr-4 
FEA results are shown in the following figures. Fig.16 reveals that at the end of the loading process, a polyurethane plug was pushed into the ring specimen. The ring bulged out at the middle section. The von Mises stress distribution in the clad is not uniform. Maximum stress occurred in the clad within the whole system, which is similar to the result in Fig. 7. The simulation results for FEM with the hyperelastic material model of polyurethane plug using the Yeoh form and the Marlow form are very close to each other, which indicate that the hyperelastic material model is reliable.

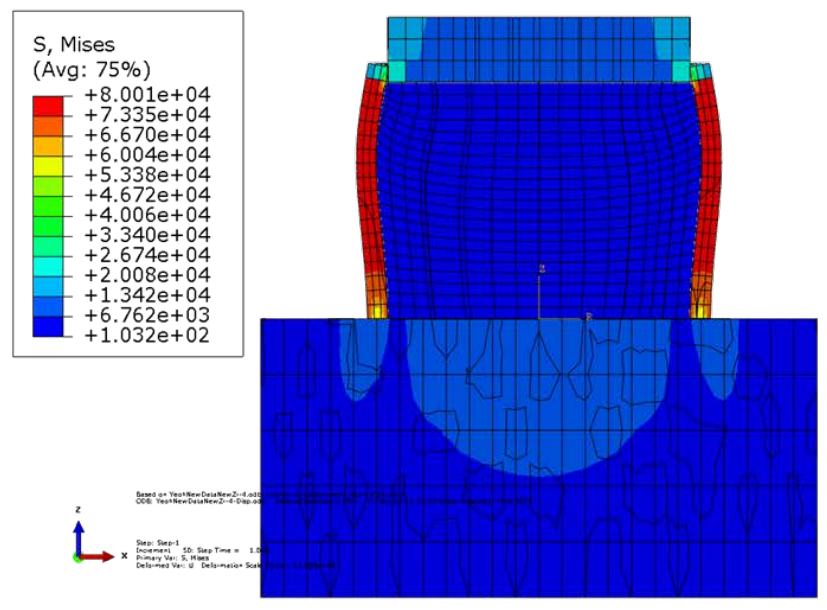

(a) Yeoh form

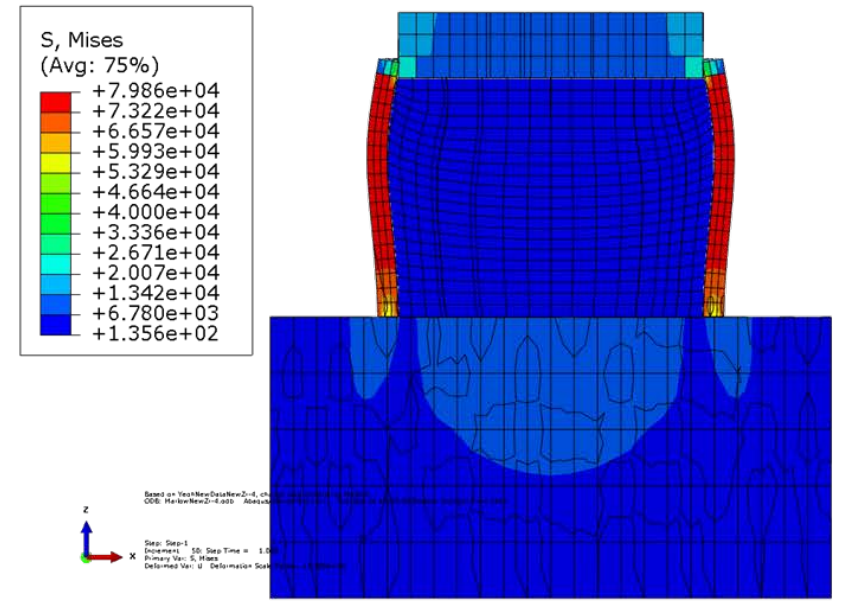

(b) Marlow form

Fig. 16 Non-uniform stress distribution in the clad for FEM with hyperelsasitc material model of polyurethane plug.

Fig. 17 shows nonuniform contact stress distribution in the clad for FEM with the hyperelastic material model of the polyurethane plug. Fig. 18 shows the radial dilatation distribution in the clad along the gage section. The hyperelastic material model using the Yeoh form or the Marlow form does not exhibit much difference in the resultant strain as well. Radial strain results in highly nonuniform distribution. Maximum strain occurs at the ring bulge-out section. Compared to the test of the unirradiated $\mathrm{Zr}-4$ ring specimen at room temperature in Fig. 19, the simulation results show a very close deformation shape.
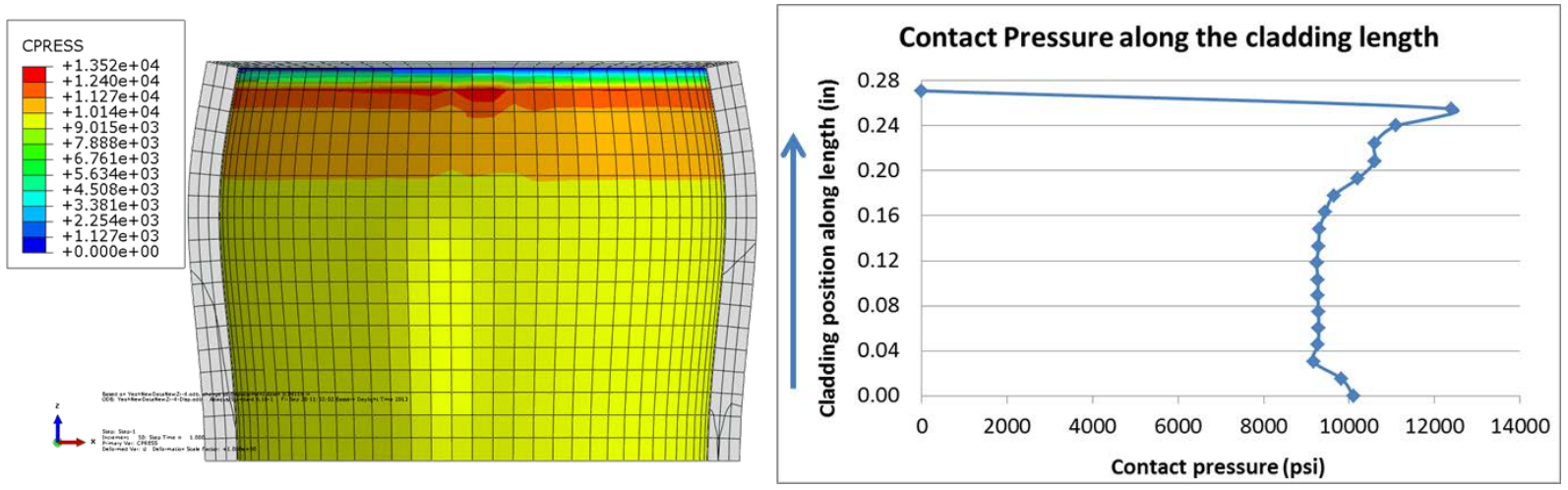

(a) Yeoh form 

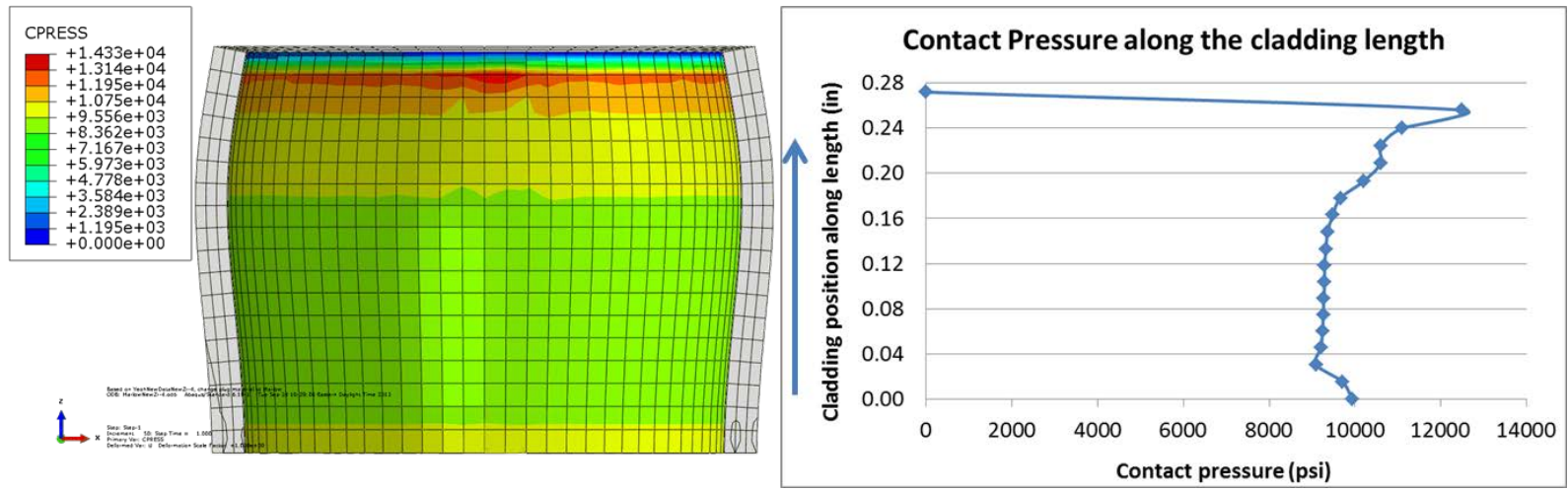

(b) Marlow form

Fig. 17 Nonuniform contact stress distribution in the clad for FEM with hyperelastic material model of polyurethane plug.
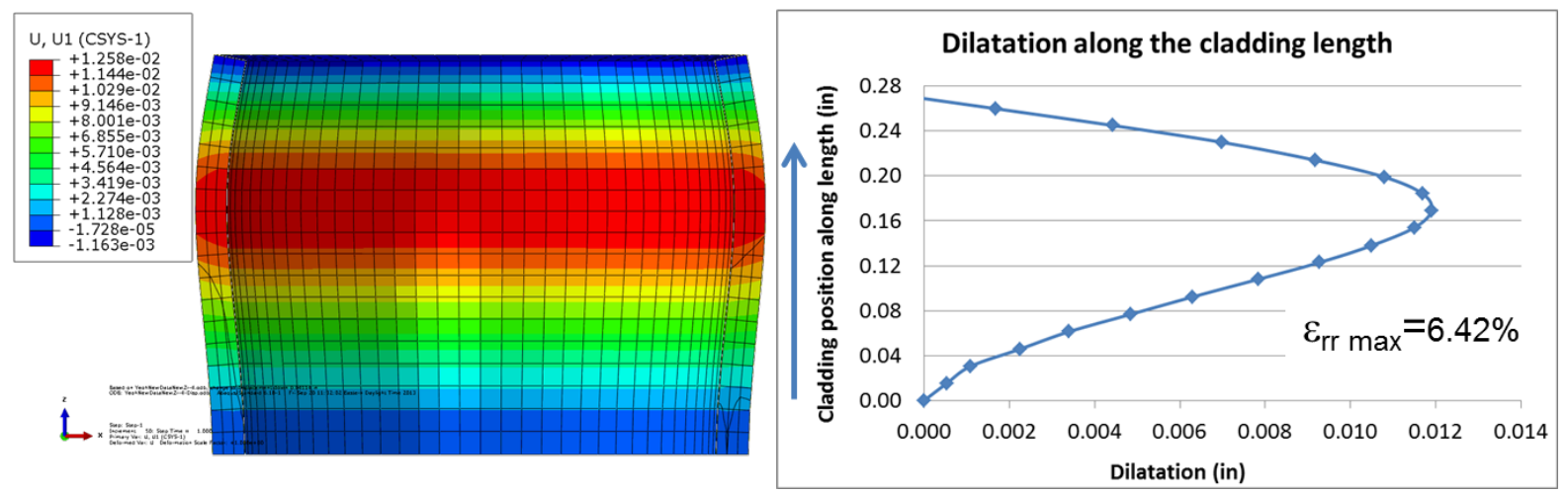

(a) Yeoh form
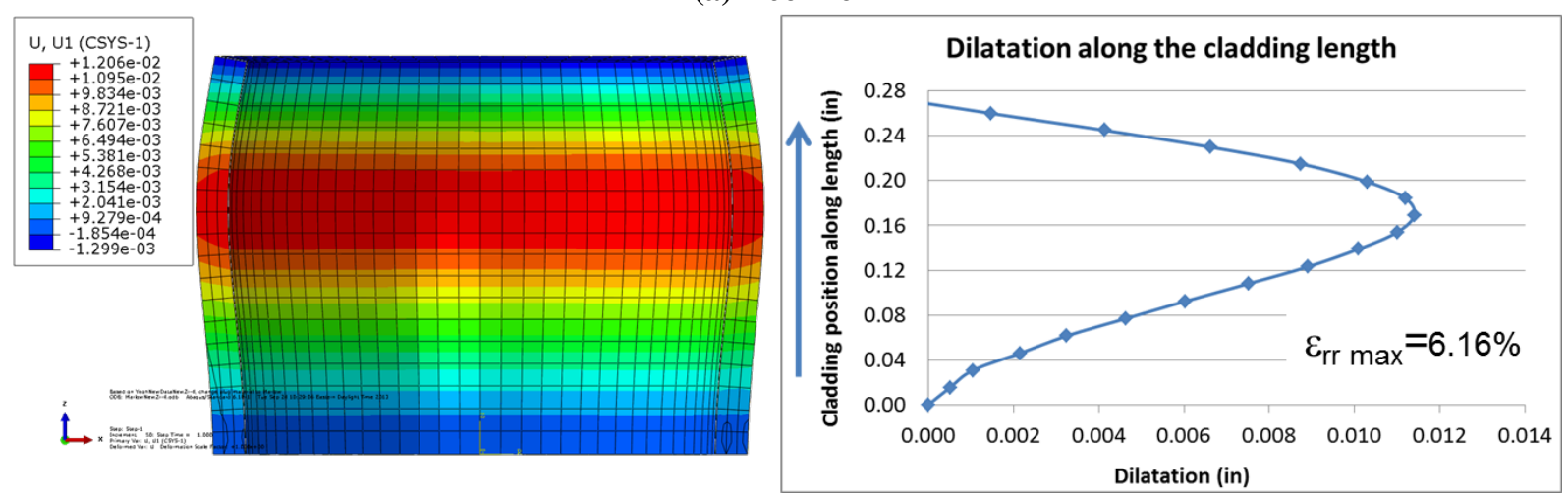

(b) Marlow form

Fig. 18 Nonuniform radial dilatation in the clad for FEM with hyperelastic material model of polyurethane plug. 


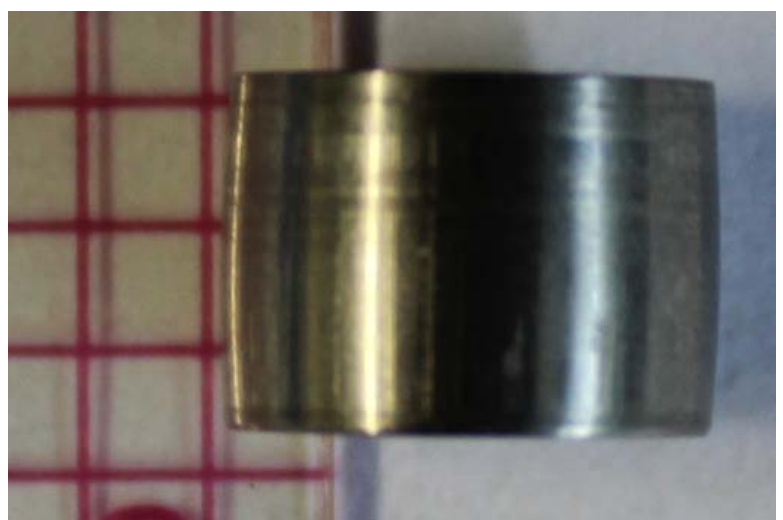

Fig. 19 Tested unirradiated $\mathrm{Zr}-4$ ring specimen at room temperature.

In ring expansion plug clad testing, the increase in diameter of the specimen was continuously monitored and recorded using non-contacting proximity transducers as shown in Fig. 20. The test apparatus used four proximity transducers to provide greater precision in the measurement of ring expansion and, therefore, to provide greater accuracy in the strain measurement. The diameter increase of the specimen was used to calculate the circumferential strain accrued during the test. Tested radial dilatation of the unirradiated Zr-4 specimen was compared with the FEA results (Fig. 18) in Table 3. The FEA results match the test data very well, within 3\% deviation. This is validation that the 3D FEM model in Fig. 11 with the hyperelasitc material model of polyurethane plug can be used to represent the ring expansion clad testing system and to evaluate the existing expanded plug method for mechanical property testing using FEA.

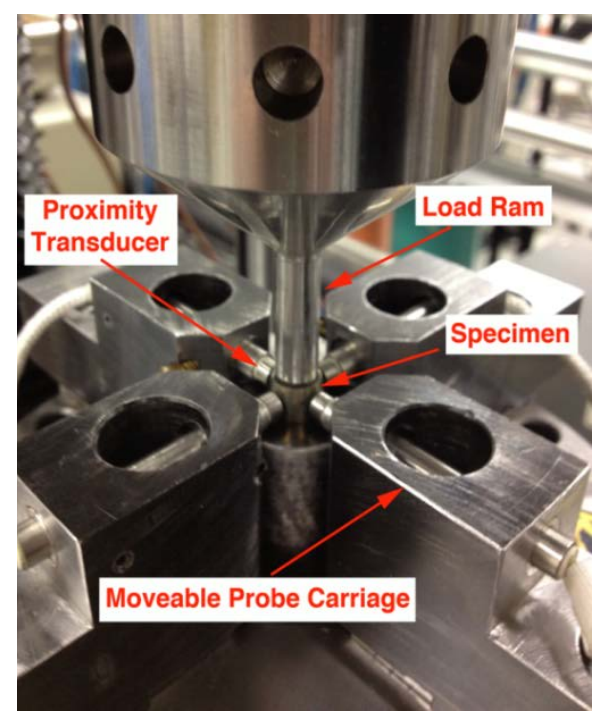

Fig. 20 Test setup for ring tensile testing using proximity transducers.

Table 3. Radial dilatation of unirradiated $\mathrm{Zr}-4$ specimen comparison between test and FEA

\begin{tabular}{lc}
\hline & $\begin{array}{c}\text { Max radial dilatation } \\
\text { (\%) }\end{array}$ \\
\hline Unirradiated Zr-4 ring test raw data $^{a}$ & 6.34 \\
Unirradiated Zr-4, hyperelastic material model of Yeoh form $^{b}$ & 6.42 \\
Unirradiated Zr-4, hyperelastic material model of Marlow form $^{b}$ & 6.16 \\
\hline
\end{tabular}

${ }^{a}$ Ref. [5], ${ }^{b}$ Fig. 18 
FEA evaluation of current expanded plug test method shows significant non-uniform stress distribution (illustrated in Fig. 16) and a highly non-uniform radial dilatation (illustrated in Fig. 18), where the typical non-uniform deformation of the expanded clad was also demonstrated with a barreling effect of the tested clad (shown in Fig. 19). This deficiency is inherent from the current expansion plug test protocol. Fig. 16 illustrates the simulated bulging phenomenon of an expanded plug test at the end of the target loading cycle. Similar bulging barrel effect for the polyurethane plug alone can be seen in Fig. 13 from a uniaxial compression test [12]. The polyurethane plug was design to be slightly longer than the clad [4]. In order to obtain enough lateral force to expand the ring, the polyurethane plug has to be fully compressed downward into the ring. In addition to the inherent plug barreling effect, the ring bulging intensity will be increased when the plug was pressed down below the top ream of the ring, as illustrated in Fig. 16. However, if a longer plug is used to prevent plug being fully pressed into the clad ring, the consequence of the potential plug buckling instability will arise and may further complicate the testing procedure.

Furthermore, significant axial compressive stresses exist in the clad bending deformation induced by the clad bulging effect. Fig. 21 shows the axial stress distribution at the middle section of the clad. The compressive stress occurs at the inner wall, while tension stress occurs at the outer wall of the clad. The associated maximum compressive stress reaches $34 \mathrm{ksi}$.

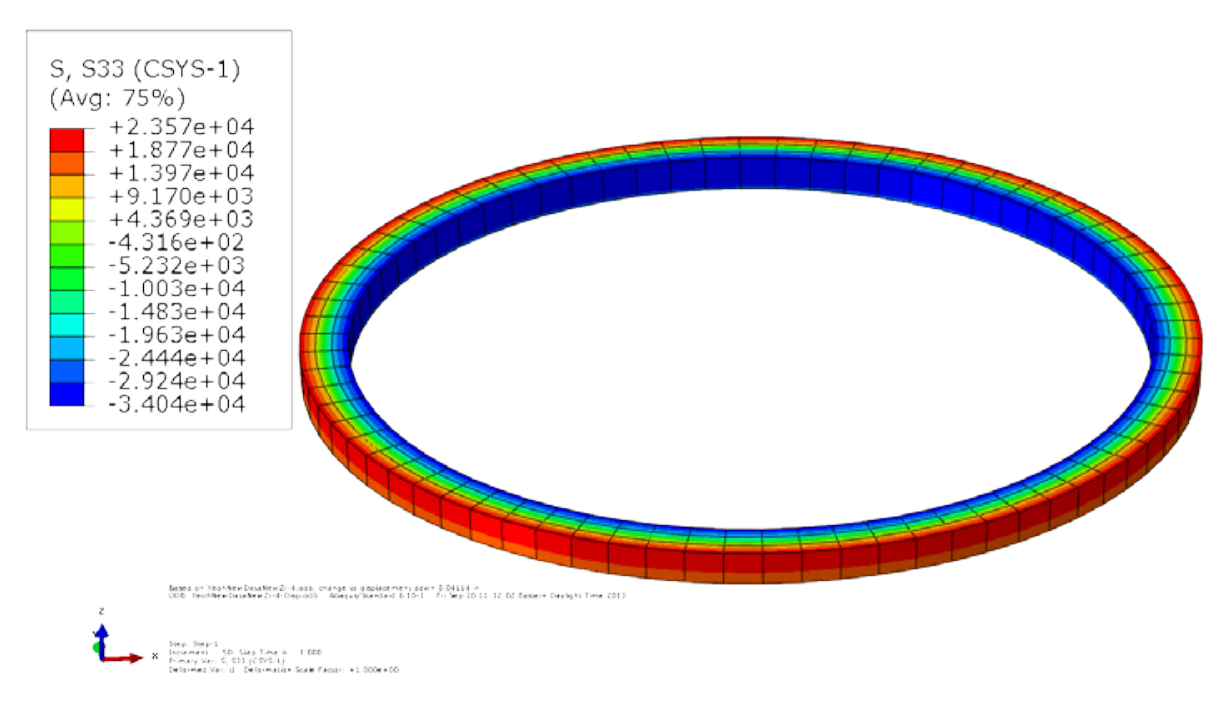

Fig. 21 The resultant axial stress in the middle section of the clad.

Table 4 shows the stress range in unirradiated Zr-4 cladding from the FEA results. Due to nonuniform distribution, the stress exhibits a wide range, especially hoop stress $\sigma_{\mathrm{TT}}$ and axial stress $\sigma_{\mathrm{Zz}}$. Significant compressive stress for $\sigma_{\mathrm{Zz}},-34 \mathrm{ksi}$, was induced by clad bending deformation due to the clad bulging effect (or the barreling effect). The barreling effect caused very large localized shear stress in the clad wall; max shear stress $=\left(\sigma_{\mathrm{TT}}-\sigma_{\mathrm{ZZ}}\right) / 2=(55.3+34) / 2=44.65 \mathrm{ksi}$. This will lead the testing material to high risk of shear failure.

Table 4. True stress range in unirradiated Zr-4 cladding from FEA results

\begin{tabular}{lccccc}
\hline & $\sigma_{\mathrm{RR}}(\mathbf{k s i})$ & $\sigma_{\mathrm{TT}}(\mathbf{k s i})$ & $\boldsymbol{\sigma}_{\mathrm{Zz}}(\mathbf{k s i})$ & $\sigma_{\mathbf{R z}}(\mathbf{k s i})$ & von Mises (ksi) \\
\hline $\begin{array}{l}\text { Hyperelastic material } \\
\text { model, Yeoh form }\end{array}$ & $-7.97 \sim-1.31$ & $55.3 \sim 86.9$ & $-34.0 \sim 23.6$ & $0.9 \sim 3.22$ & $78.9 \sim 79.8$ \\
\hline
\end{tabular}


As shown in Fig. 22(a), inside the pressurized cylinder, the axial stress is in tension, on the basis of thinwalled cylinder theory. However, significant compressive stress profiles were observed in the expansion plug tested clad. Compressive stress in cladding can further induce lateral expansion of the clad wall, in addition to that induced by the internal pressure provided by the plug lateral expansion. So the sources of lateral expansion in a plug expansion test include two parts: (1) internal pressure induced by plug lateral expansion and (2) lateral bulging deflection induced compressive/tension bending stress in the clad and minor lateral shear stress at inner clad wall, as shown in Fig. 22(b).

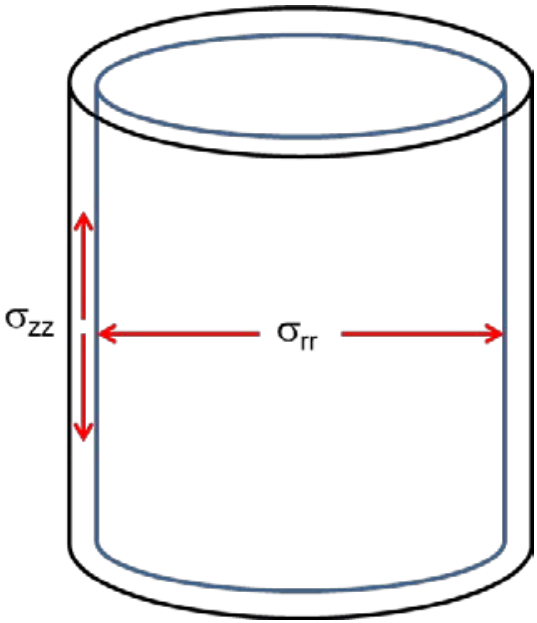

(a) Pressurized cylinder (axial stress is in tension)

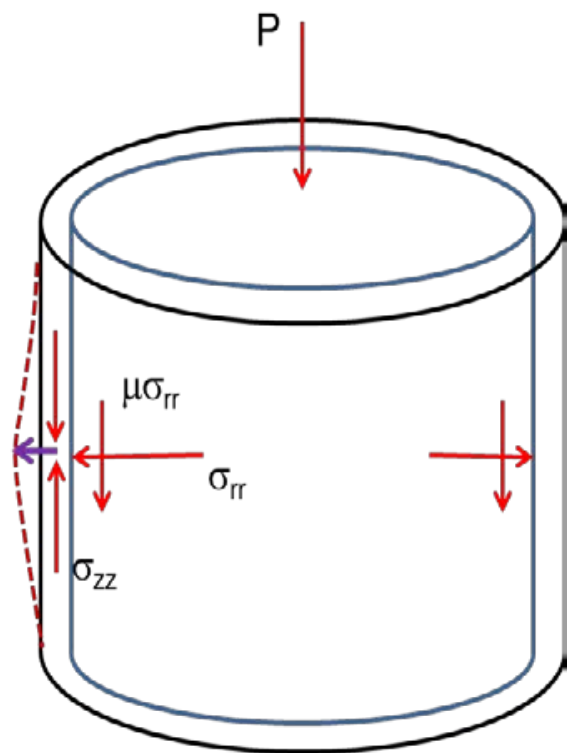

(b) Expansion plug test (axial stress is in compression)

Fig. 22 Sketch of stress comparison between pressured cylinder and expansion plug test.

Fig. 23 shows Mohr's circles for determining localized failure contour. Mohr's circles demonstrate that shear failure could be the dominant failure mode of the expansion plug test. In a typical pressurized cylinder stress profile as shown in Fig. 23(a), hoop stress is about 2 times that of axial stress for a thin shell; however, in a typical expansion test clad stress profile, hoop stress is about 3 times that of axial stress, and axial stress becomes compressive stress, as shown in Fig. 23(b). Based on the above finding, the maximum shear stress for an expansion plug test would be much larger than that of a typical pressurized vessel; thus the expansion plug tested clad can result in a shear failure with the fracture plane at $45^{\circ}$ to that of axial orientation, as indicated in Fig. 24 of failure samples from [14]. This is in contrast to the conventional pressure vessel rupture test, where axial split fracture is normally observed, as shown in Fig. 25, reproduced from [15]. Therefore, shear failure mode could be the dominant failure mode in the 
expansion plug test.

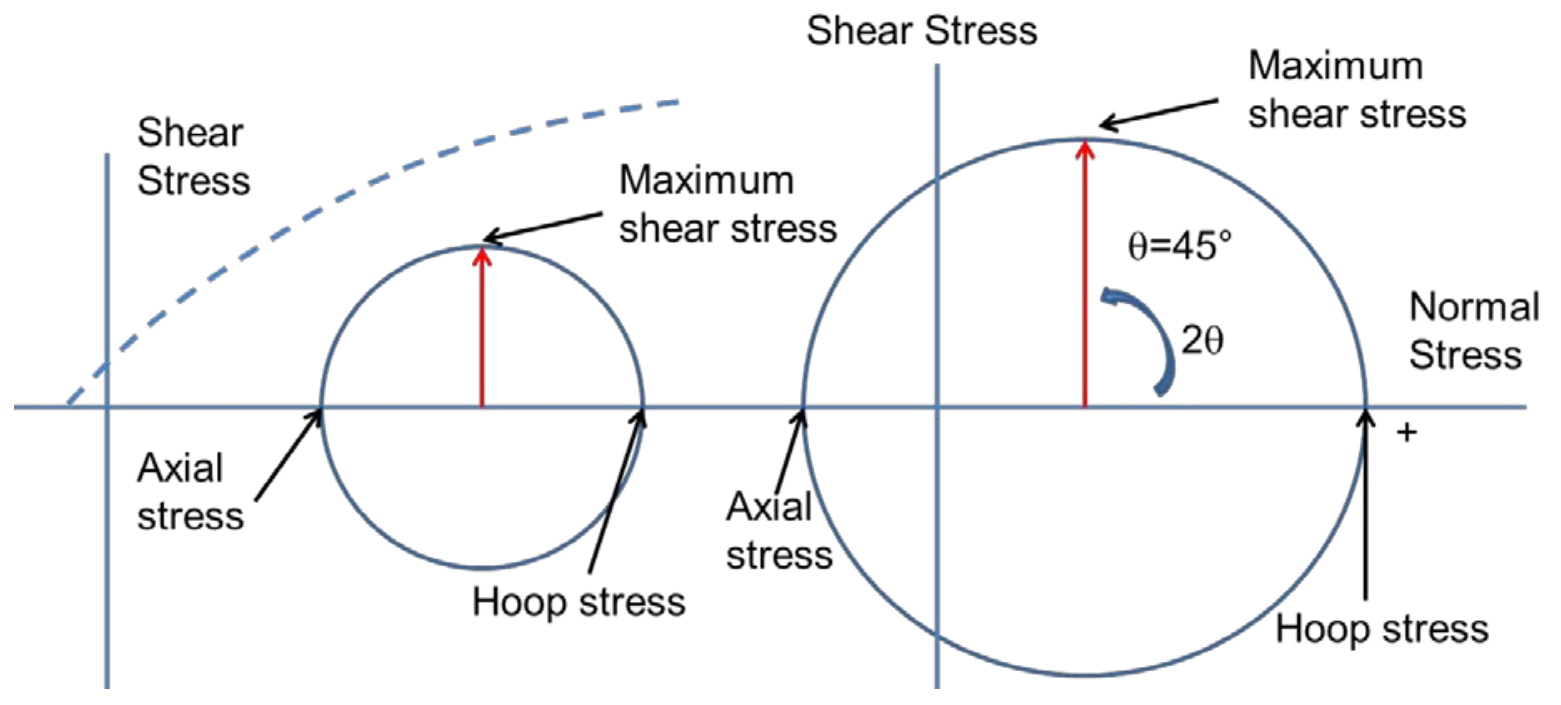

(a) Typical cylinder stress profile

(b) Typical expansion plug stress profile Fig. 23 Mohr's circles demonstrate the potential shear failure.
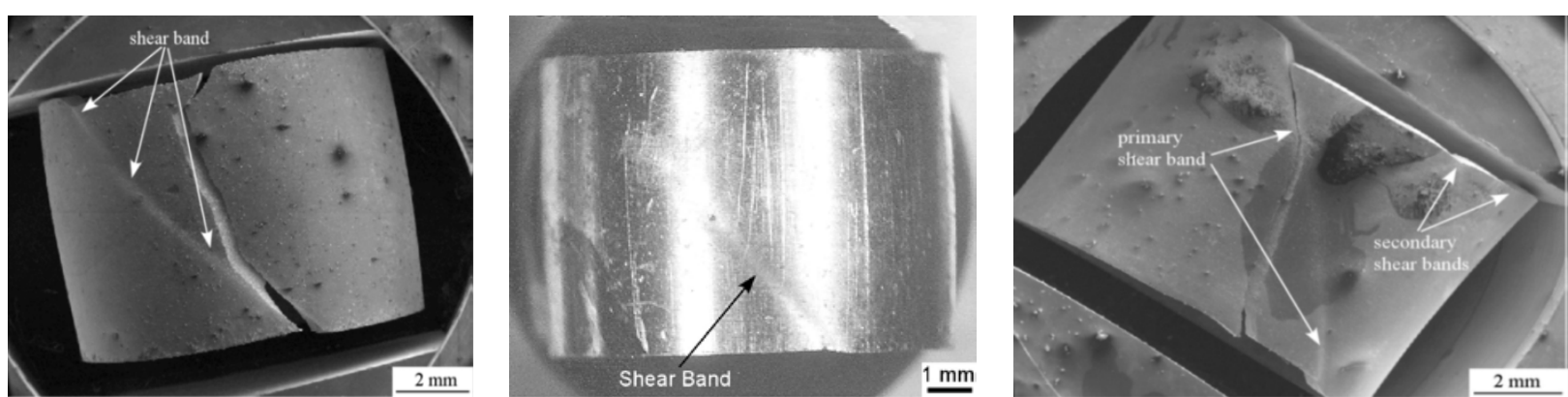

Fig. 24 Fuel cladding failed samples. Source: [14].

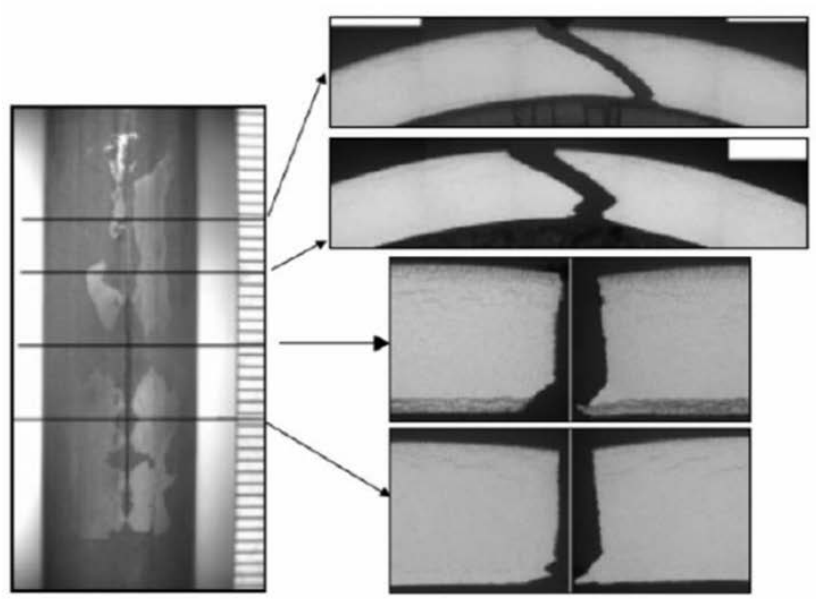

FIG 5.50. Visual appearance and cross-sectional metallography of a failed segment rod (irradiated five cycles, RTP: $446 \mathrm{~W} / \mathrm{cm}$, failed after $22 \mathrm{~min}$ hold).

Fig. 25 Typical axial splitting in high-burnup clad. Source: [15]. 
Furthermore, FEA result for ductile materials indicates that the failure mode of the expanded ring can be a shear failure mode with a fracture plane at $45^{\circ}$ inclined to the axial direction of the tested ring; however this is not normally observed in a pressurized pipe rupture failure.

The circumferential strain estimated from the expansion plug test overestimates the strain deformation due to that the proximity transducers can only detect the maximum radial expansion of the ring. Thus, in a highly non-uniform radial dilatation profile shown in, using the maximum radial strain to represent the hoop strain level will significantly overestimate the material deformation. This deficiency was also revealed by a round-robin test result for Zr-4 clad material, as shown in Table 5 [14]. At room temperature, the available elongation data from ORNL appears to be much larger than other organizations' test results, where the expanded plug method was used in ORNL test approach.

Table 5. Summary of round-robin test results for Zr-4 clad from Ref. [14]

\begin{tabular}{|c|c|c|c|c|c|c|}
\hline $\begin{array}{c}\mathrm{T} \\
\left({ }^{\circ} \mathrm{C}\right)\end{array}$ & Organization & $\begin{array}{c}\text { Yield } \\
\text { Strength } \\
(\mathrm{MPa})\end{array}$ & $\begin{array}{c}\text { Ultimate } \\
\text { Strength } \\
(\mathrm{MPa})\end{array}$ & $\begin{array}{c}\text { Uniform } \\
\text { Elongation } \\
(\%)\end{array}$ & $\begin{array}{c}\text { Total } \\
\text { Elongation } \\
(\%)\end{array}$ & $\begin{array}{c}\text { Meas. } \\
\text { Total } \\
\text { Elongation } \\
(\%)\end{array}$ \\
\hline $20 \pm 2$ & ANL & $698 \pm 7$ & $767 \pm 8$ & $2.1 \pm 0.5$ & $8 \pm 1$ & ---- \\
\hline & & & & & & \\
\hline 32 & CEA & $667 \pm 15$ & $767 \pm 3$ & $3.0 \pm 0.3$ & $23 \pm 0$ & ---- \\
\hline RT & EdF & $707 \pm 15$ & $782 \pm 0$ & $1.6 \pm 0.1$ & $17 \pm 0$ & ---- \\
\hline & & & & & & \\
\hline RT & JAERI & $708 \pm 15$ & $807 \pm 1$ & $3.8 \pm 0.2$ & $41 \pm 0$ & $37 \pm 3$ \\
\hline 33 & RRC-KI/RIAR & $\mathrm{TBD}^{\mathrm{a}}$ & $\mathrm{TBD}^{\mathrm{a}}$ & $\mathrm{TBD}^{\mathrm{a}}$ & $\mathrm{TBD}^{\mathrm{a}}$ & ---- \\
\hline & & & & & & \\
\hline RT & ORNL & $703 \pm 8^{\mathrm{a}}$ & $>793^{\mathrm{a}}$ & $>8^{\mathrm{a}}$ & $\mathrm{a}$ & $\mathrm{a}$ \\
\hline
\end{tabular}

(a) Was not measured in ORNL tests

The other deficiency of the current expanded plug method is that the bottom of the ring specimen is in a direct contact with the support post, as shown in Fig. 11. During the expanded plug testing, the ring experiences a downward drag force against the support post owing to the induced shear stress between the plug and the ring. As a result, the reaction force from the support post causes a significant compressive stress and the associated shear stress in the ring, as illustrated in Fig. 26. The maximum compressive axial stress of 100ksi occurs at the bottom area of the ring shown in Fig. 26(a). At the contact surface of the ring, shear stress reaches the maximum of 13.9ksi, shown in Fig. 26(b). 


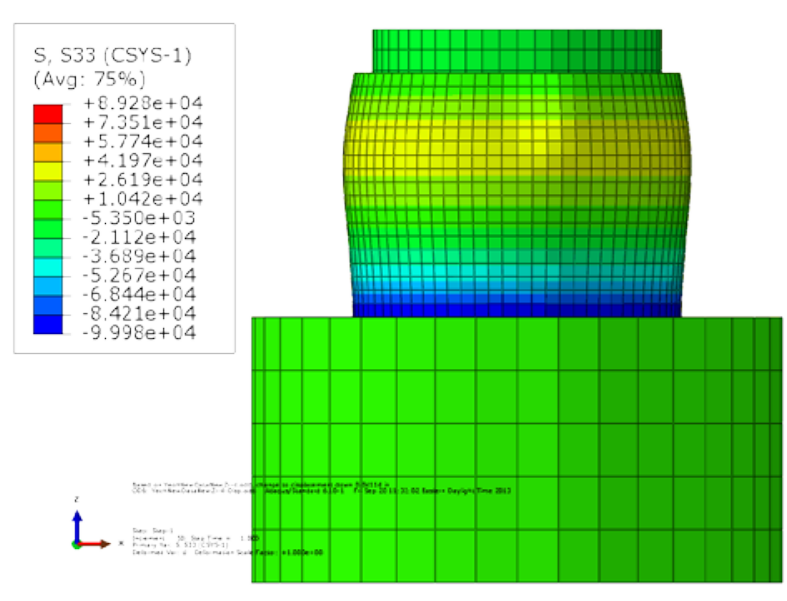

(a) Axial stress

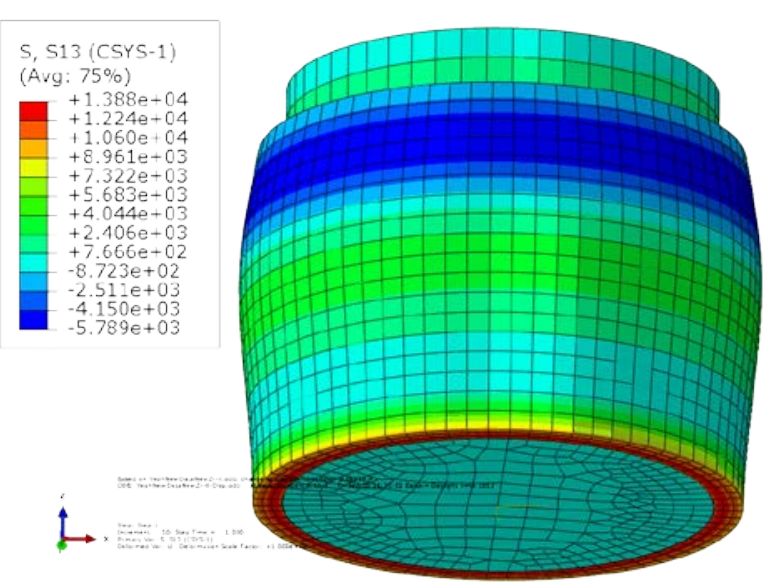

(b) Shear stress

Fig. 26 Resultant stress distribution in current expansion plug testing system.

As discussed above, the significant compressive axial stress and shear stress in a plug-clad testing system cannot be ignored. To mitigate this deficiency, the testing system has to prevent the ring in a direct contact with the support post.

\subsection{FEA OF ELEVATED TEMPERATURE $\left(350^{\circ} \mathrm{C}\right)$ RING EXPANSION CLAD TESTING}

At the elevated temperature $350^{\circ} \mathrm{C}$, copper was selected as the expansion plug material for the current expanded plug test. As shown in Fig. 27, the FEM model of the ring expansion clad test system with copper plug at elevated temperature followed the room temperature model discussed in Fig. 11. The ring specimen in this FEA study was SRA Zircaloy-4. Ram and support still used high strength steel. The geometry of the SRA Zircaloy-4 ring specimen remained the same as that of the unirradiated Zr-4 specimen, while the geometry of the copper plug changed according to the test setup. The copper plug had a length of $0.29 \mathrm{in}$. and an OD of $0.324 \mathrm{in}$., which enlarged the initial gap to $0.001 \mathrm{in}$. Loading and boundary conditions, as well as contact condition, were the same as in the room-temperature model.

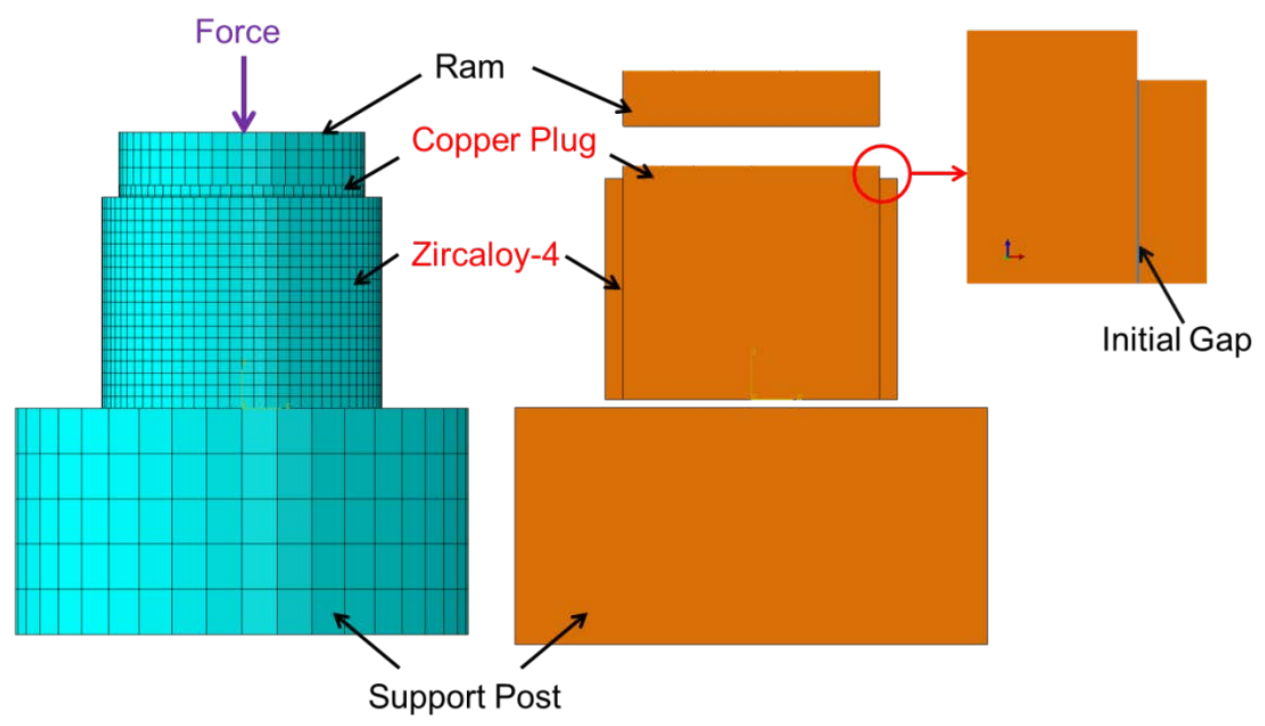

Fig. 27 3D FEM model of ring expansion clad test system with copper plug at elevated temperature. 
Fig. 28 shows the copper plug material property test data at $350^{\circ} \mathrm{C}$, provided by James G. Hemrick. Data indicated highly plastic material behavior for copper at the elevated temperature. Therefore, the deformation plasticity material model in ABAQUS/CAE was chosen to simulate copper plug behavior during the expansion plug test at $350^{\circ} \mathrm{r}$ Tmm. parameters of the deformation plastic model were calibrated from test data. The compc SRA rial properties are summarized in Table 6. SRA Zircaloy-4 material data at $350^{\circ} \mathrm{C}$ were from Michelle Flanagan of NRC in supporting the spent fuel vibration integrity program. Both unirradiated and irradiated SRA Zircaloy-4 claddings were simulated, and results were compared side by side.

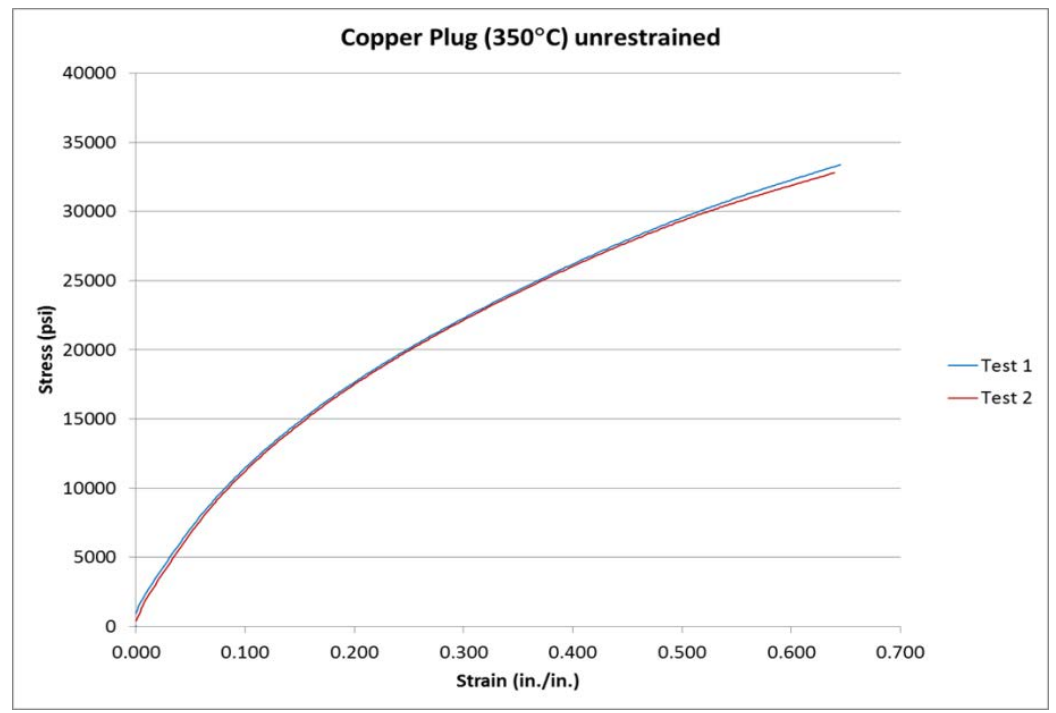

Fig. 28 Copper plug material property test data at $350^{\circ} \mathrm{C}$.

Table 6. Summary of component material properties for FEA at elevated temperature

\begin{tabular}{lccccc}
\hline & $\begin{array}{c}\text { Young's } \\
\text { modulus (psi) }\end{array}$ & $\begin{array}{c}\text { Poisson's } \\
\text { ratio }\end{array}$ & $\begin{array}{c}\text { Yield stress } \\
\text { (psi) }\end{array}$ & $\begin{array}{c}\text { Hardening } \\
\text { exponent }\end{array}$ & $\begin{array}{c}\text { Yield } \\
\text { offset }\end{array}$ \\
\hline Copper: deformation plastic model & 153,000 & 0.306 & 5,000 & 1.18 & $0.2 \%$ \\
Unirradiated SRA Zircaloy-4 at & $9.18 \times 10^{6}$ & 0.353 & 54,195 & & \\
$350^{\circ} \mathrm{C}^{a}$ & & & & \\
Irradiated $\left(1.20 \mathrm{E}+26 \mathrm{n} / \mathrm{m}^{2}\right)$ SRA & $10.4 \times 10^{6}$ & 0.353 & 88,993 & \\
${\text { Zircaloy-4 at } 350^{\circ} \mathrm{C}^{a}}$ & & & \\
High strength steel $^{b}$ & $3.0 \times 10^{7}$ & 0.28 & 280,000 & \\
\hline
\end{tabular}

${ }^{a}$ Ref. [17]

${ }^{b}$ Ref. [11]

Stress distribution in the ring expansion clad testing system at $350^{\circ} \mathrm{C}$ from FEA results is shown in Fig. 29. Typical load stresses for testing at $350^{\circ} \mathrm{C}$ were on the order of $45 \mathrm{ksi}$ (ring hoop stress) for unirradiated material and $85 \mathrm{ksi}$ for irradiated material tests. This corresponds to loads on the order of $2300 \mathrm{lbf}$ and $3325 \mathrm{lbf}$ of axial load on the copper plug, respectively (cited from J. Hemrick). Similar to room-temperature FEA results, the stress distribution is nonuniform and SRA $\mathrm{Zr}-4$ rings bulge at the middle of the gage section. The stress distributions in both unirradiated and irradiated SRA Zr-4 cladding appear similar. Table 7 summarizes the stress ranges resulting in SRA Zr- 4 cladding at $350^{\circ} \mathrm{C}$. Irradiated 
SRA Zr-4 cladding under higher loading experiences a higher stress level than unirradiated SRA Zr-4 cladding. Similar to room-temperature results, significant compressive stress was observed in $\sigma_{\mathrm{ZZ}}$, which was induced by the clad bulging effect. Maximum shear $=\left(\sigma_{\mathrm{TT}}-\sigma_{\mathrm{ZZ}}\right) / 2=(48,435+32,462) / 2=40,448$ psi for unirradiated SRA Zr-4 cladding.

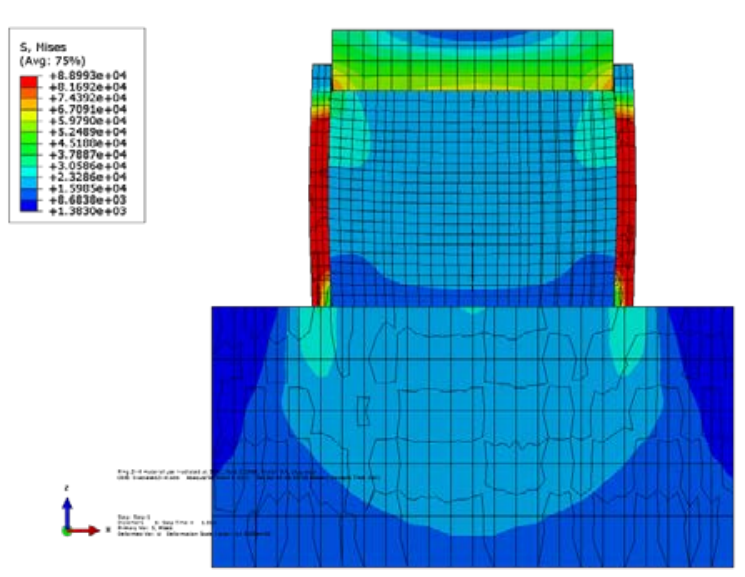

(a) Irradiated SRA Zr-4 ring, load $3325 \mathrm{lbf}$

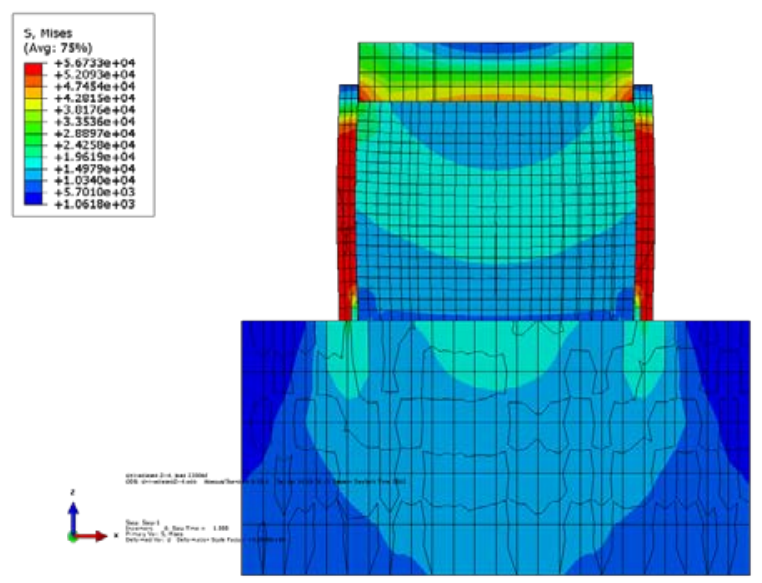

(b) Unirradiated SRA Zr-4 ring, load $2300 \mathrm{lbf}$ Fig. 29 Nonuniform stress distribution in SRA Zr-4 clad for FEM with deformation plastic material model of copper plug at $350^{\circ} \mathrm{C}$.

Table 7. Stress range in SRA Zircaloy- 4 cladding from FEA results at $350^{\circ} \mathrm{C}$

\begin{tabular}{cccccc}
\hline & $\sigma_{\mathrm{RR}}(\mathbf{p s i})$ & $\sigma_{\mathrm{TT}}(\mathbf{p s i})$ & $\sigma_{\mathrm{ZZ}}(\mathbf{p s i})$ & $\sigma_{\mathrm{RZ}}(\mathbf{p s i})$ & von Mises (psi) \\
\hline Irradiated Zr-4 & $-7798 \sim-1273$ & $48713 \sim 83191$ & $-53180 \sim-9229$ & $874 \sim 6011$ & 88993 \\
Unirradiated Zr-4 & $-4246 \sim-767$ & $29649 \sim 48435$ & $-32462 \sim-9374$ & $674 \sim 3502$ & 54195 \\
\hline
\end{tabular}
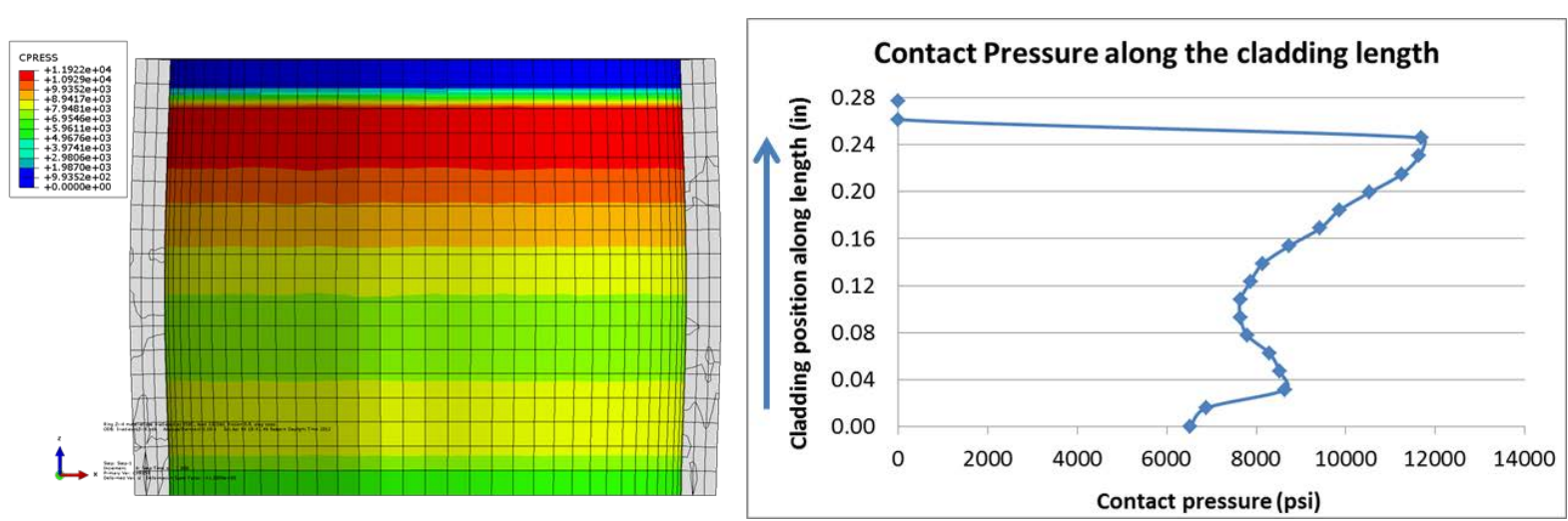

(a) Irradiated SRA Zr-4 ring, load 3325 lbf 

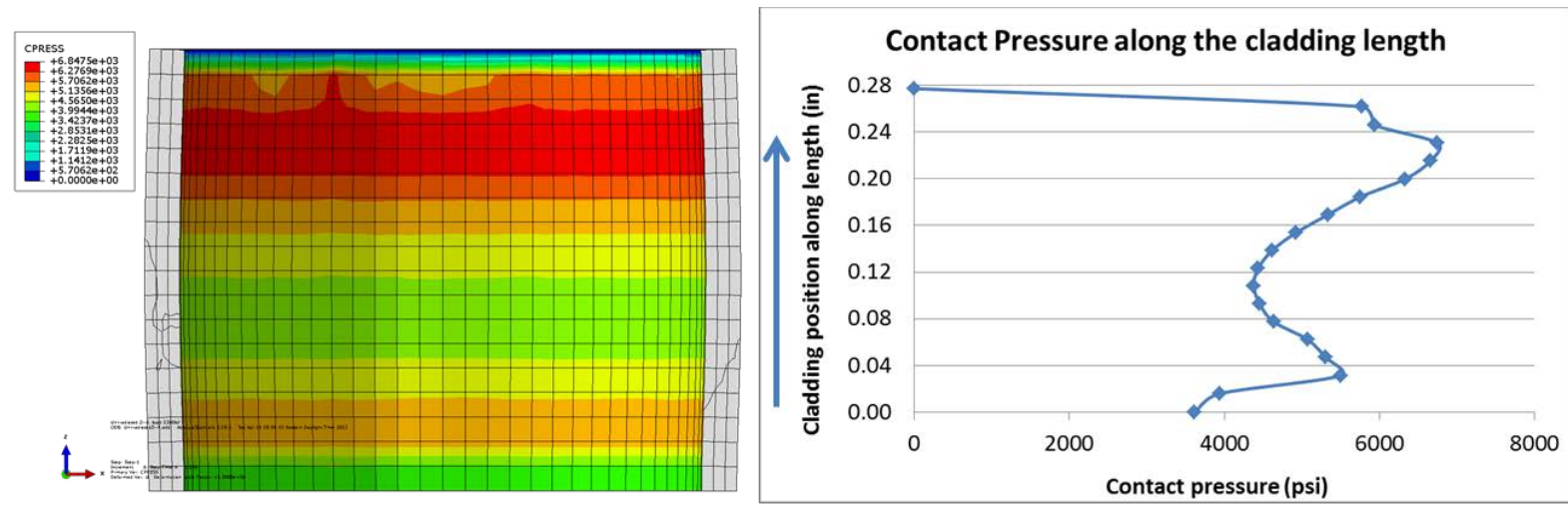

(b) Unirradiated SRA Zr-4 ring, load 2300 lbf

Fig. 30 Nonuniform contact stress distribution in SRA Zr-4 clad for FEM with deformation plastic material model of copper plug at $350^{\circ} \mathrm{C}$.
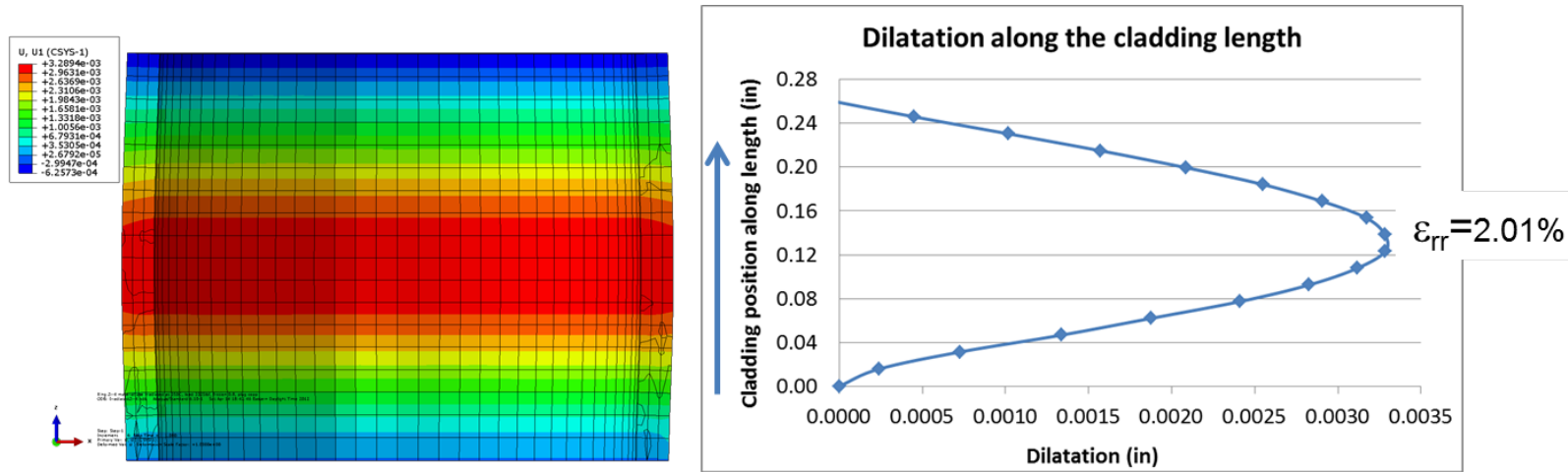

(a) Irradiated SRA Zr-4 ring, load 3325 lbf

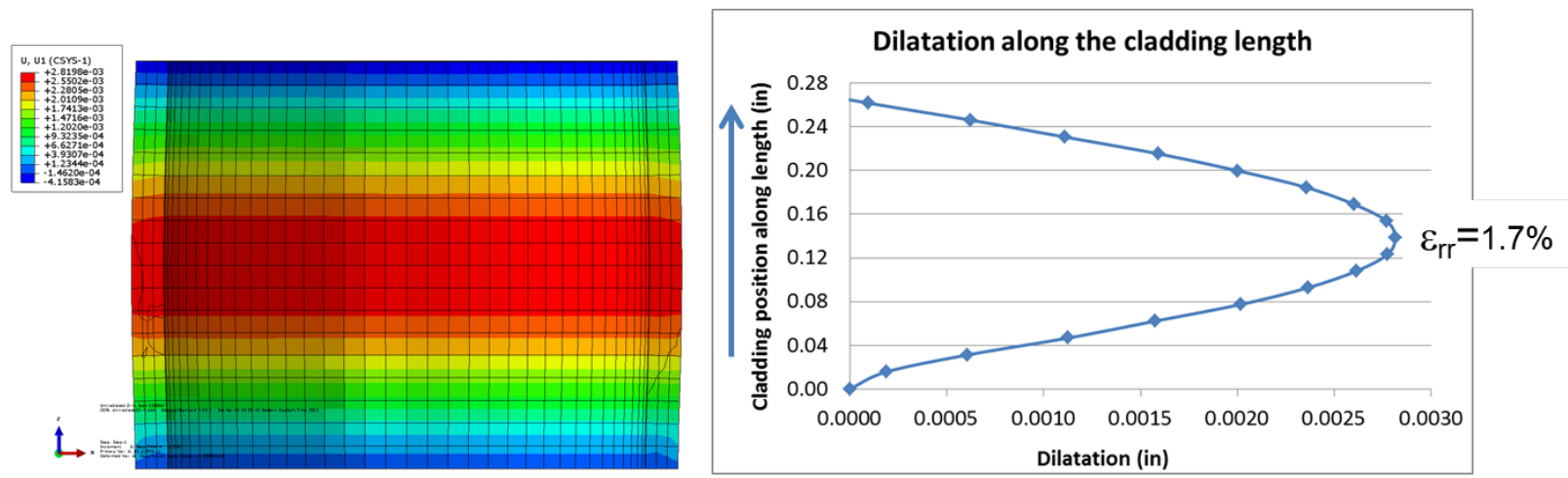

(b) Unirradiated SRA Zr-4 ring, load 2300 lbf

Fig. 31 Nonuniform radial dilatation in SRA Zr-4 clad for FEM with deformation plastic material model of copper plug at $350^{\circ} \mathrm{C}$. 


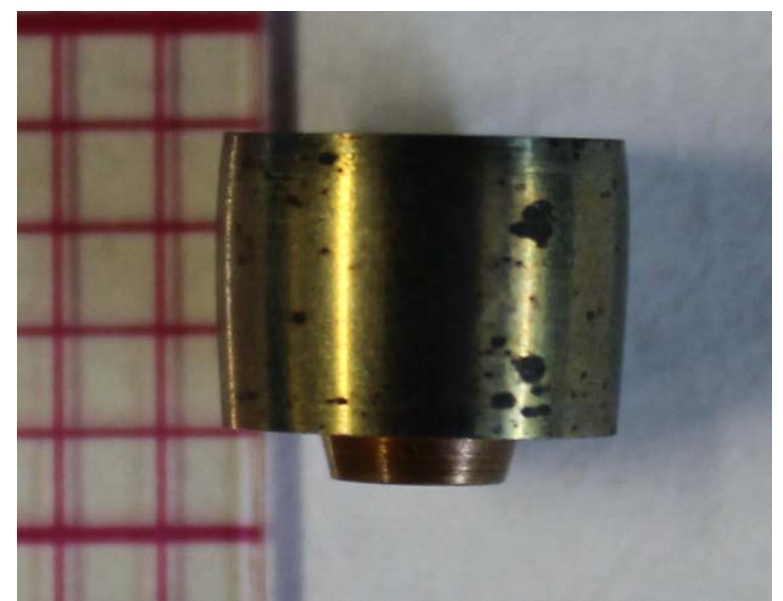

Fig. 32 Tested unirradiated ring specimen with copper plug.

Fig. 30 shows nonuniform contact stress distribution in SRA Zr-4 clad for FEM with the deformation plastic material model of copper plug at $350^{\circ} \mathrm{C}$. Fig. 31 shows nonuniform radial dilatation distribution along the gage length. FEA results are similar to those of unirradiated $\mathrm{Zr}-4$ cladding at room temperature. Maximum radial strain occurs at the cladding bulge-out section, $2.01 \%$ for irradiated SRA Zr-4 cladding and $1.7 \%$ for unirradiated SRA Zr-4 cladding. Fig. 32 shows the deformed test specimen. The ring specimen bulges at the middle of gage section, similar to FEA. However, it was learned from the irradiated test that uniform elongation of the irradiated ring specimen is $\sim 3.4 \%$, which is much higher than the maximum FEM radial strain. 


\section{DEVELOPMENT OF EXPANDED PLUG WEDGE TEST}

Finite element simulations on the previously developed ORNL expanded plug test show significant nonuniform stress distribution and highly nonuniform radial dilatation in the expansion plug tested clad. The barreling effect produces significant bending stress into the clad wall, both tensile and compressive stress in the same cross section. This will result in a very large localized shear stress field in the clad wall portion that has compressive stress. To mitigate the mentioned deficiencies associated with the current expansion plug test, systematic studies have been conducted. A method to reconcile the potential nonconservatism embedded in the expansion plug test system has been discovered. The expanded plug wedge test has been developed based on the method.

\subsection{FIRST DESIGN MODIFICATION OF THE EXPANDED PLUG TEST}

The first proposed modification of the expanded plug test is to choose aluminum as the material for the expansion plug instead of polyurethane, as shown in Fig. 33. The test design is as simple as the previous ORNL design. An axial compressive load is applied to a cylindrical plug of aluminum. As the plug is pressed down, it expands in the radial direction. In the process, radial extension of the outside ring of test material can be obtained. Similarly, the load-circumferential strain data from the ring tests will be converted into material stress-strain curves in a separate procedure.

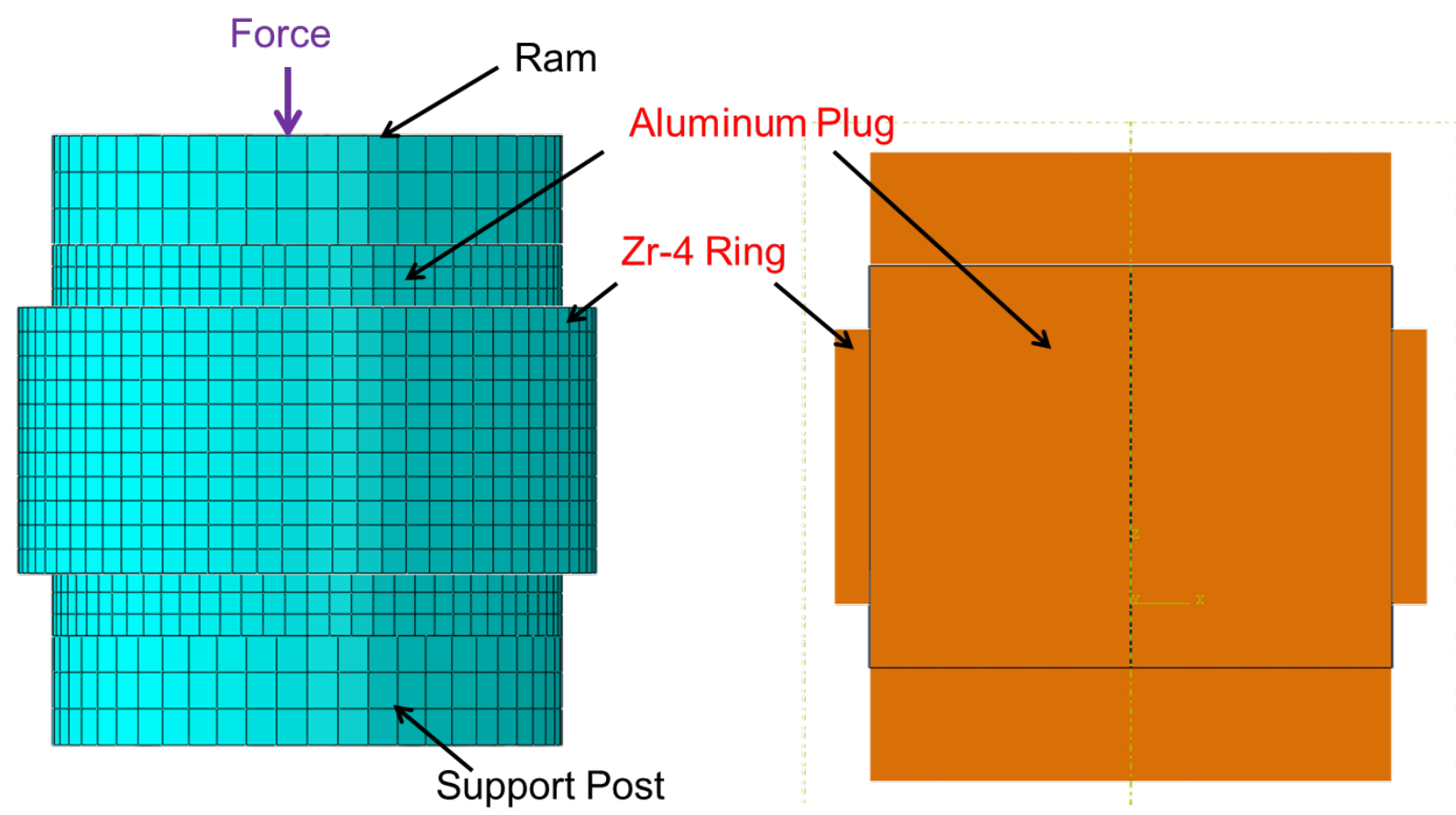

Fig. 33 FEM model of first proposed design modification.

There are three main differences between the proposed expanded plug wedge test design and the previous ORNL design. Beside the difference choice of plug material, the axial length of the test specimen is shorter than in the previous design. A series of size effect studies for the axial length of the clad and expansion plug have been performed. From these recent systematic investigations, an optimized length has been determined that will produce a more uniform stress and strain distribution within the gage section. The third difference lies in the friction in the interface between clad and plug. Lubrication is considered in the interface in order to reduce the interfacial shear stress and the consequence of axial compressive stress. 
In Fig. 33, the geometry of this first design modification model has been optimized in FEA. The length of the ring is shorter, 0.17 in., and OD and ID of the ring are the same as in the current ORNL design, 0.37 and 0.326 in., respectively. OD of the plug is 0.326 in. The plug length is 0.25 in. The bottom surface was constrained to 6 DOF in the FEM model. Pressure load was applied on the top of the ram. The general contact was defined as between the outer surface of the expanded plug and the inner surface of the ring specimen. The friction in the interface between clad and plug were set to 0.04 [20] to simulate the lubrication effect. Ring material is still unirradiated Zr-4. Plug material is aluminum 6061-T6. Ram and supported are still high strength steel. The component material properties are listed in Table 8.

Table 8. Component material properties of the first design modification

\begin{tabular}{lccc}
\hline & Young's modulus (psi) & Tensile yield stress (psi) & Poisson's ratio \\
\hline Unirradiated Zr-4 $^{a}$ & $1.44 \times 10^{7}$ & 67,800 & 0.37 \\
High strength steel $^{b}$ & $3.0 \times 10^{7}$ & 280,000 & 0.28 \\
Aluminum 6061-T6 $^{c}$ & $1.0 \times 10^{7}$ & 40,000 & 0.33 \\
\hline
\end{tabular}

${ }^{a}$ Ref. [5]

${ }^{b}$ Ref. [11]

${ }^{c}$ Ref. [18]

FEM simulation results exhibit apparent improvement in the stress and strain distribution at the gage section, as shown in Fig. 34 and Fig. 35. However, the stress and strain distributions are not perfectly uniform to meet the design requirement.

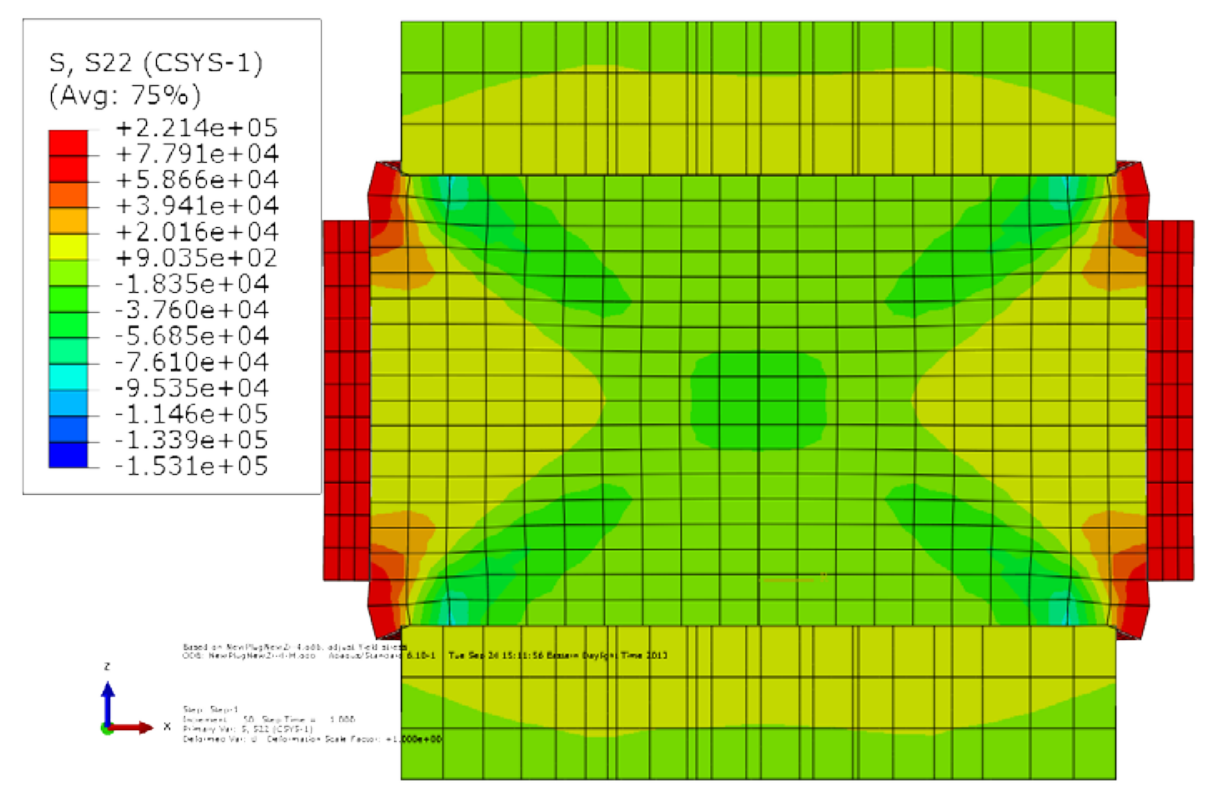

Fig. 34 Improved stress distribution in the clad for the first design modification. 


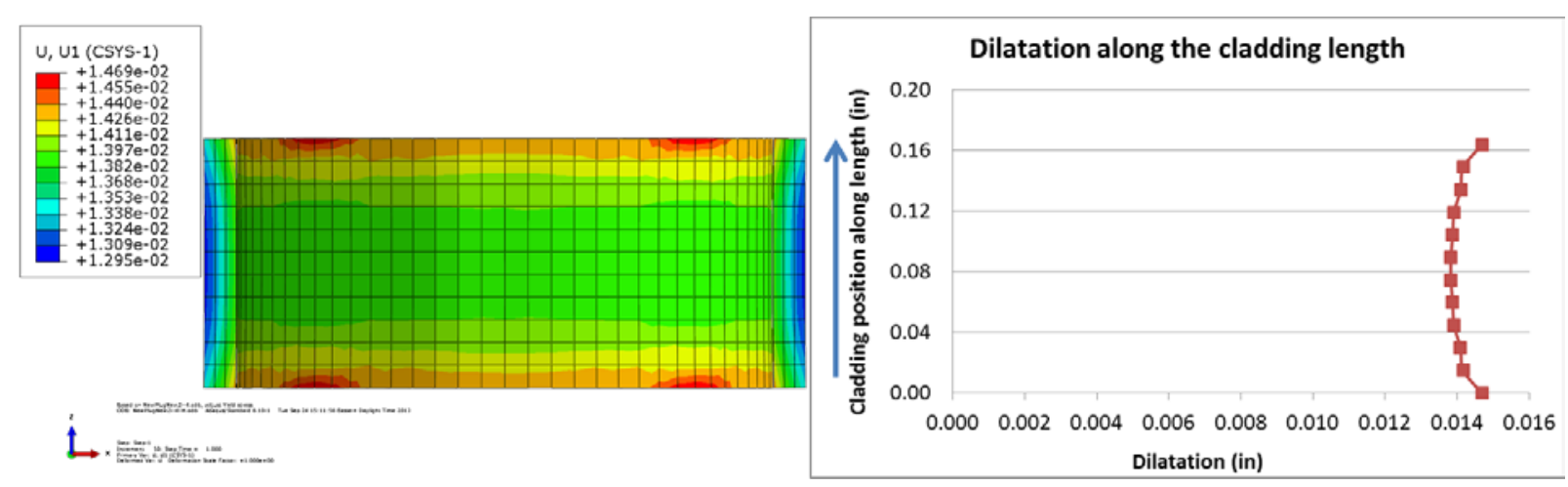

Fig. 35 Improved radial dilatation distribution at the gage section for the first design modification.

Fig. 36 shows that the compressive stress and shear stress are also significantly reduced from the new design. The resultant compressive stress and shear stress are one order of magnitude less than that of the current design in Fig. 26.

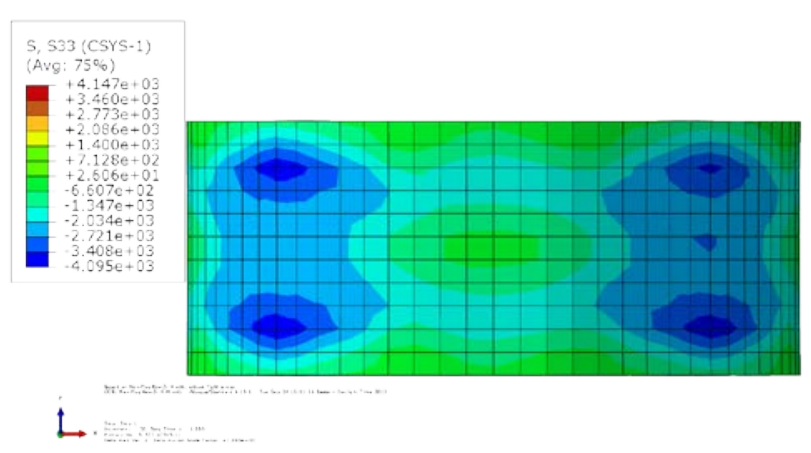

(a) Axial stress

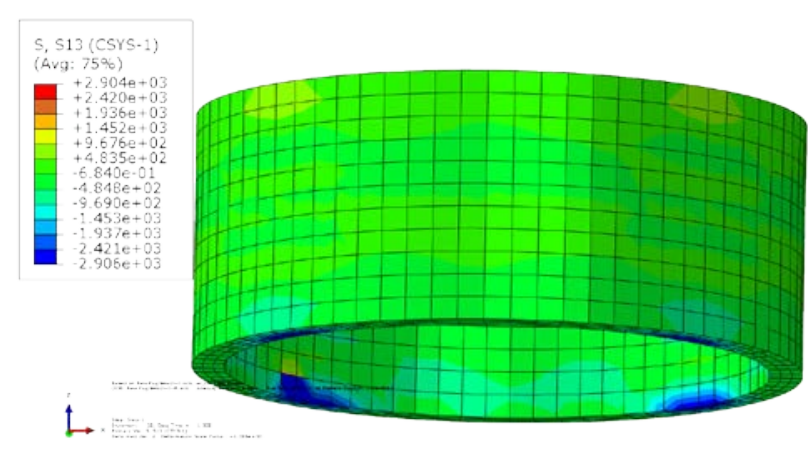

(b) Shear stress

Fig. 36 Axial stress and shear stress distribution in the clad for the first design modification.

\subsection{EXPANDED PLUG WEDGE TEST}

In addition to the first proposed modification, an expanded plug test has been developed with rigid wedges inserted between clad and plug. The FEM model of this version of design modification is shown in Fig. 37. The working mechanism is similar to the other expanded plug test designs. However, as the eight rigid wedge pieces are introduced in-between the tested ring and plug, the expanded plug is not directly pressing on the test specimen (reducing the impact of the plug bulging effect to ring deformation). The compressive plug pushes against the rigid wedges moving in the outward radial direction, by which the stress and deformation are transferred onto the tested ring. 


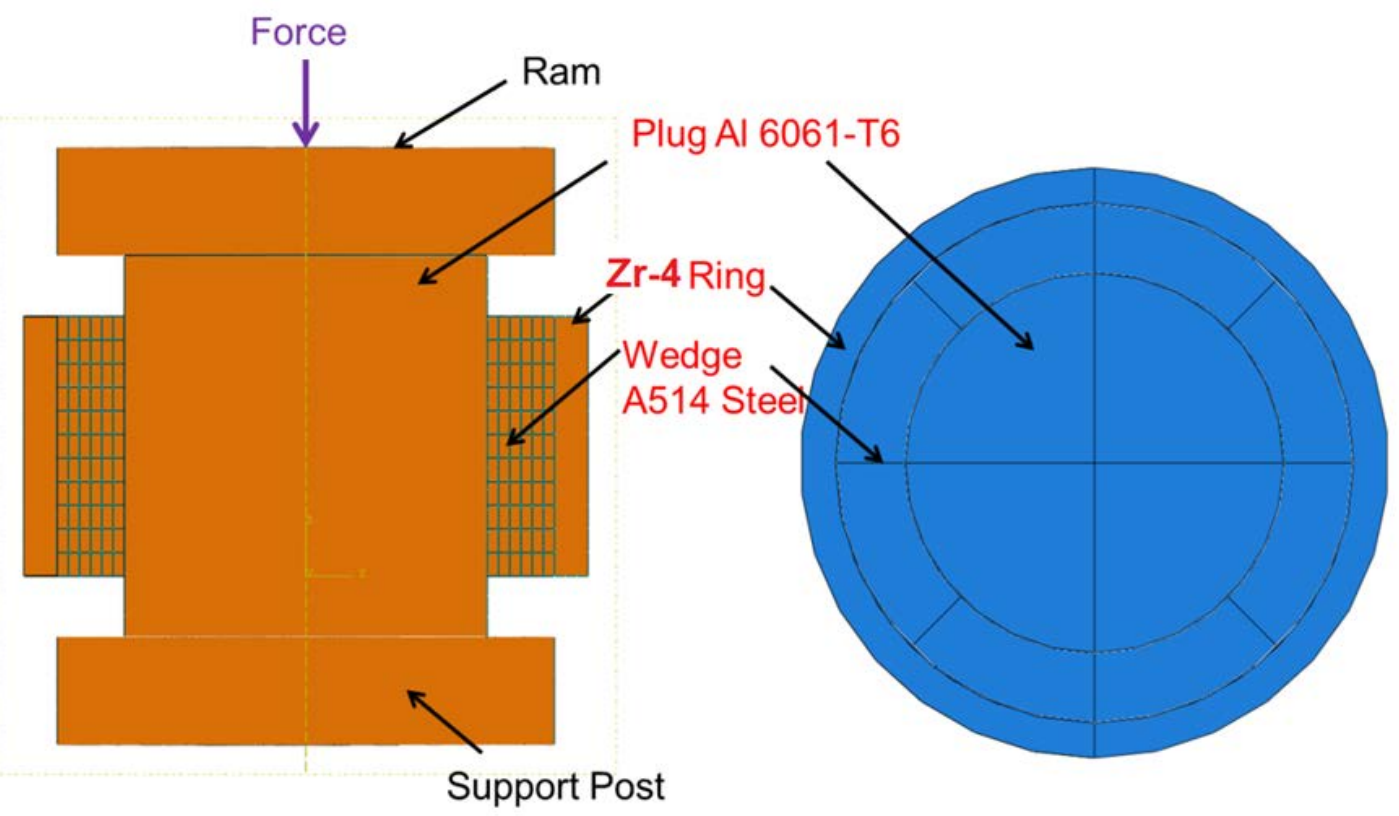

Fig. 37 FEM model of expanded plug wedge test design.

Through detailed parameter investigation on the specific geometry designs, the expanded plug wedge test design has an optimized geometry, as modeled in Fig. 37. Especially for the wedge inserts, several iterations of the FEA study had to be performed to reach the final design. Once the essential thickness of the wedge was determined, the OD and ID of the wedge were decided accordingly. The plug diameter has been modified accordingly with respect to the inserted wedges. To achieve even expansion in the radial direction of the ring specimen, the wedge inserts were cut into eight pieces. The geometry of the specimen ring is the same as that of the first modification, as well as the axial length of the plug. The ring length is 0.17 in., OD is 0.37 in., and ID is 0.326 in. The wedges are rigid with eight pieces. The length of the wedges is 0.17 in., ID is 0.238 in., and OD is 0.326 , corresponding to the ring's ID. Hence, the thickness of the wedges is $0.044 \mathrm{in}$. The plug length is $0.25 \mathrm{in}$., and the OD of the plug is $0.238 \mathrm{in}$., corresponding to the wedge's ID.

Material selection for the testing system is crucial. After careful filtering, A514 steel was chosen for the wedge inserts and aluminum 6061-T6 was used for the expansion plug. Ring material is unirradiated Zr-4. The ram and support port are still high strength steel. The component material properties of testing system are listed in Table 9.

Table 9. Component material properties of expanded plug wedge test

\begin{tabular}{|c|c|c|c|}
\hline & Young's modulus (psi) & Tensile yield stress (psi) & Poisson's ratio \\
\hline Unirradiated $\mathrm{Zr}-4^{a}$ & $1.44 \times 10^{7}$ & 67,800 & 0.37 \\
\hline High strength steel ${ }^{b}$ & $3.0 \times 10^{7}$ & 280,000 & 0.28 \\
\hline Aluminum $6061-\mathrm{T6}^{c}$ & $1.0 \times 10^{7}$ & 40,000 & 0.33 \\
\hline A514 steel ${ }^{d}$ & $2.97 \times 10^{7}$ & 100,000 & 0.285 \\
\hline
\end{tabular}

${ }^{a}$ Ref. [5]

${ }^{b}$ Ref. [11]

${ }^{c}$ Ref. [18]

${ }^{d}$ Ref. [19]. 
In the FEM model in Fig. 37, the loading and boundary conditions were the same as in the FEM model in Fig. 33 for the first modification design. The difference was the contact. Due to the wedge insert between clad and expansion plug, general contact was defined as both in the interface between the wedges and plug and the interface between clad and wedges. Low friction was also applied in those interfaces to reduce shear stress.

Fig. 36 shows the uniform hoop stress distribution in the cladding for the expanded plug wedge test. There is no apparent bulging observed in the clad wall. Fig. 37 shows a uniform radial dilatation distribution along the gage length. Along the clad gauge section, the radial dilation is bounded between 0.02 in. and 0.022 in., which is dramatically improved from the highly non-uniform dilation of the current design. Therefore, the FEM simulation has confirmed that the proposed approach improves the uniformity of stress and strain distributions at the gage section. The results also indicate the wedge inserts work well to eliminate the bugling effect.

It also results in a more uniform stress distribution at contact interfaces between wedge and ring. It is noted that a deformed ring is not perfectly round in the radial direction. At the wedge opening section, the ring is concave; at the wedge and ring contact section, the ring is convex. The wedge and ring contact section (convex section) is much larger than the wedge opening section (concave section). FEA results show that the resultant stress-strain curves in the convex section are a better match with tensile data than that in the concave section. Therefore, circumferential measurement is suggested at the convex section in the testing.
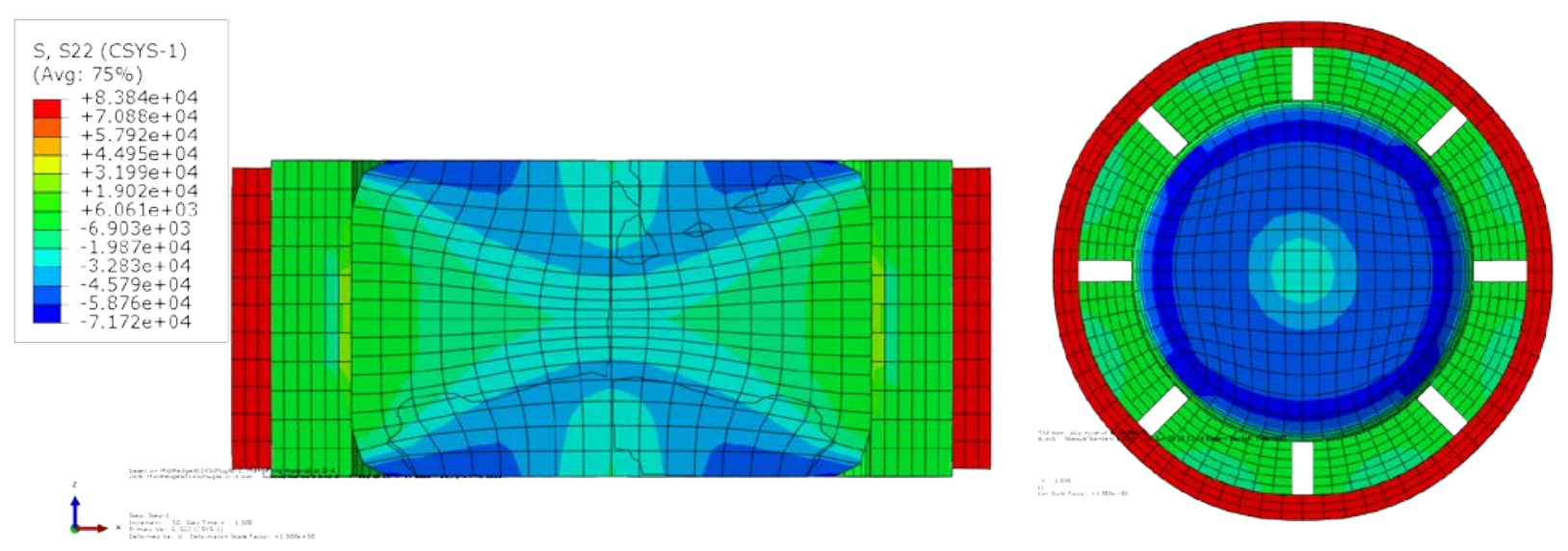

Fig. 38 Uniform stress distribution in the clad for expanded plug wedge test. 


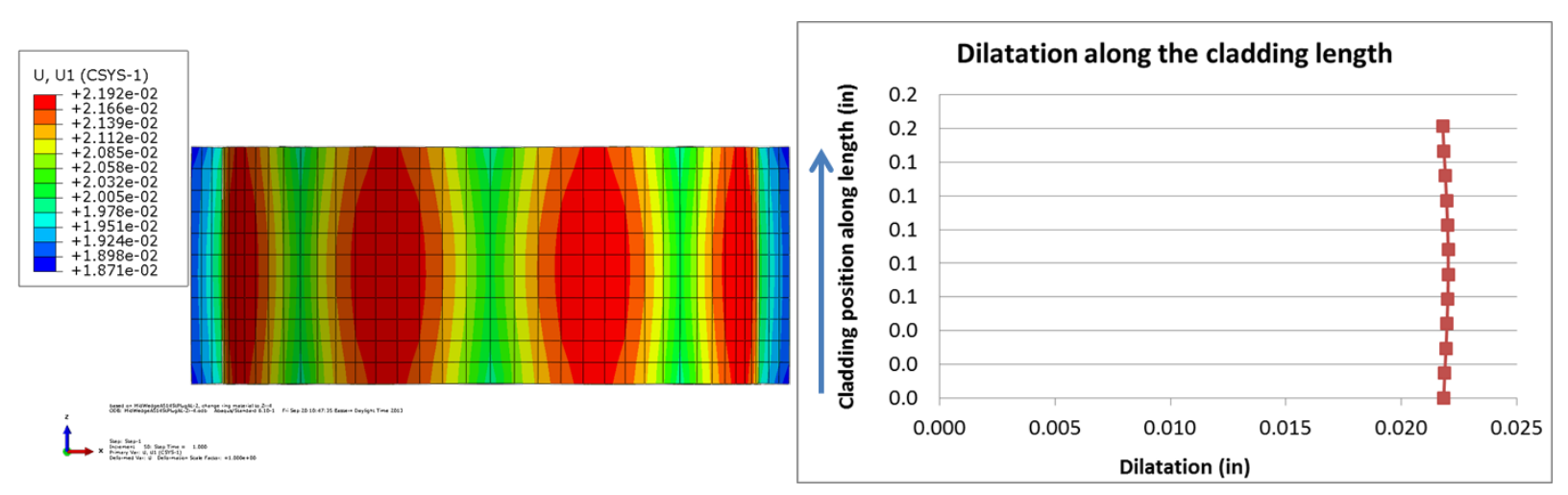

Fig. 39 Uniform radial dilatation distribution at the gage section for expanded plug wedge test.

At the gauge section, in addition to the improvement of the uniform stress and strain distribution, the compressive stress and shear stress are also significantly reduced from the new design, as shown in Fig. 40. The resultant compressive stress and shear stress are one order of magnitude less than that of the current design in Fig. 26.

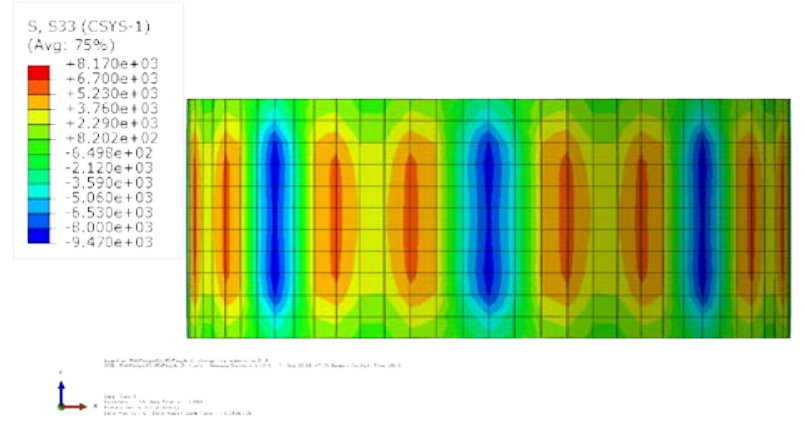

(a) Axial stress

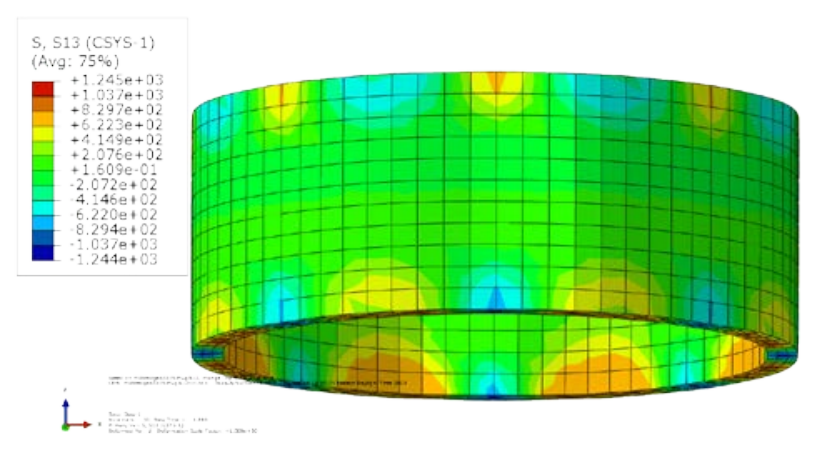

(b) Shear stress

Fig. 40 Axial stress and shear stress distribution in the clad for expanded plug wedge test.

A general procedure also has been developed to determine the hoop stress $\sigma_{\theta}$ in the tested ring specimen. Similar to the current expanded plug test method, expanded plug wedge test method is designed to extract mechanical properties for the cladding materials by converting the test load and radial expansion data into the hoop stress-strain curves. Then the mechanical properties such as Young's modulus, yield strength and strain-hardening characteristics can be examined accordingly from the material stress-strain curves.

Three key measurements need to be made in the expanded plug testing. One is the total load, $\mathrm{F}_{\text {total }}$, applied by the test frame to the plug and ring specimen, which is equivalent to the force applied to the loading ram in FEA. The second one is the amount of compression extension $\Delta \mathrm{L}$ experienced by the plug as measured by the crosshead movement, which is equivalent to the displacement of the loading ram in axial direction of the ring in FEA. The third one is the radial deformation $\Delta \mathrm{r}$ of the ring specimen as measured by the transducers, which is equivalent to the ring dilatation in the radial direction in FEA. However, the total load $\mathrm{F}_{\text {total }}$ is not totally transmitted to the ring specimen through the expansion of the plug, because a large amount of force or energy is consumed by the plug deformation. By measuring the plug load, $\mathrm{F}_{\text {plug, }}$ and compression extension $\Delta \mathrm{L}$ from a standalone plug without a ring specimen, a correlation can be developed to separate the plug load from the total load, by which the net load transmitted directly to the ring specimen can be estimated and refers to as the ring load $\mathrm{F}_{\text {ring. }}$ 
Therefore, there are two set of tests required in developing expanded plug wedge testing protocol, one is the expansion plug test with the ring specimen, and the other one is the plug compression test without the ring specimen. The total load $\mathrm{F}_{\text {total }}$ applied to the plug and ring specimen and the plug load $\mathrm{F}_{\text {plug }}$ of the free

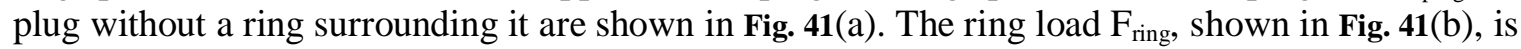
estimated from the total load $\mathrm{F}_{\text {total }}$ and the plug load $\mathrm{F}_{\text {plug }}$ based on a developed correlation procedure, as described below.

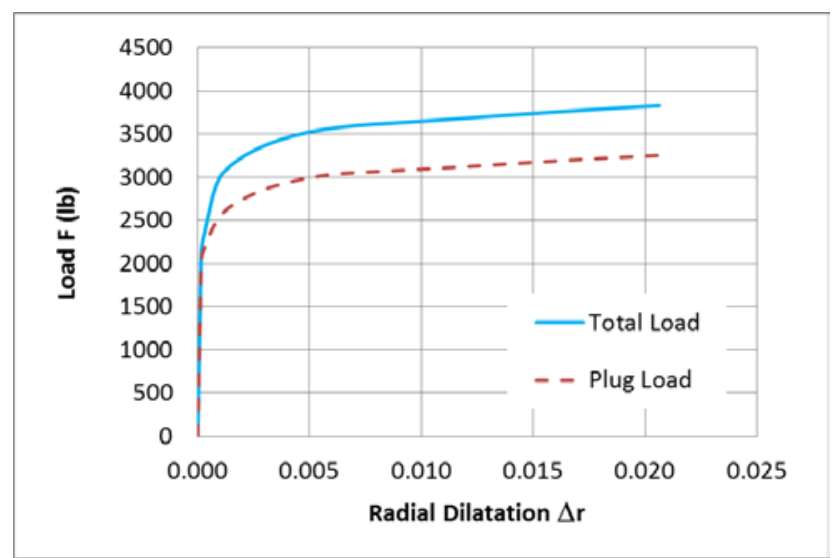

(a)

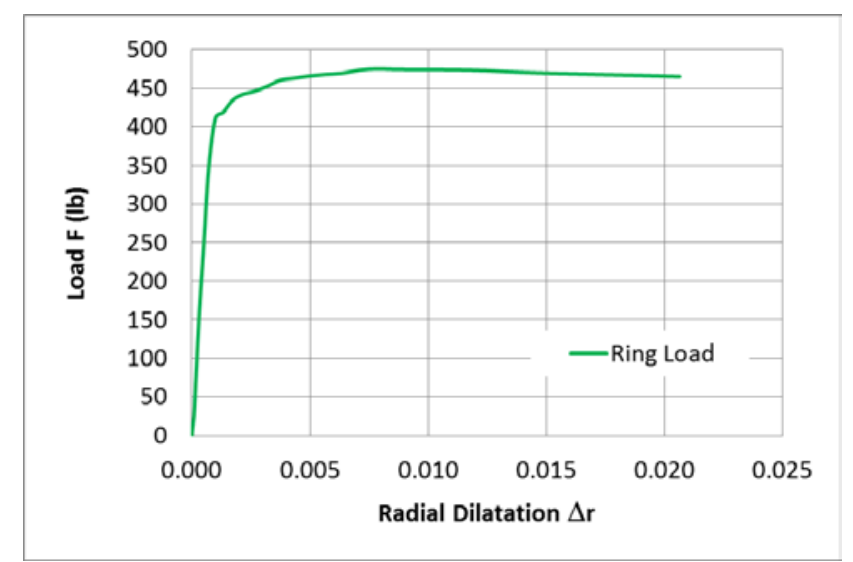

(b)

Fig. 41 Ring load determined by total load and plug load in expanded plug wedge test design

The energy conservation can be expressed in the following equations for the expansion plug ring test,

$$
\text { External Work = Internal Strain Energy }
$$

The external work is the work done by the total load $\mathrm{F}_{\text {total }}$. Internal strain energy consists of three system components, i.e., strain energy of the plug, the ring, and the wedge inserts. Internal energy also includes the energy dissipation due to friction, Thus, the Eq.(4) can be written as

Work $_{\text {total }}=$ Strain Energy plug + Strain Energy ring + Strain Energy wedge + Energy dissipation $_{\text {system }}$

The rigid-wedge inserts are designed to transmit the load uniformly onto the ring specimen. Wedges are made of high strength steel and designed to be separated during the expansion process, thus, they will consume very limited strain energy. Energy dissipation from the system is considered to be very small compared to that in plug and ring specimen due to significant reductions in compressive stress and shear stress in the new design. FEA results further verify that strain energy of wedges and energy dissipation from the friction together are only $0.3 \%$ of internal strain energy. Therefore, the last two terms in Eq. (5) were not considered in the further testing protocol development.

Strain energy of the plug with a ring surrounding it is slightly higher than the work of the free plug without a ring, due to the ring confinement contribution. FEA finds that the strain energy of the plug with a ring is $1.7 \%$ more than that of the free plug. By applying a small correction factor $\lambda$, strain energy of the plug in a ring test can be replaced by the work from the plug load $\mathrm{F}_{\text {plug }}$ of the free plug without a ring. Strain energy of the ring specimen can be expressed as nominal internal pressure $\mathrm{P}_{\text {ring }}$ acting on the ring internal area and moving $\Delta \mathrm{r}$ in the radial direction, thus, Eq. (5) can be rewritten as,

$$
\mathrm{F}_{\text {total }} \Delta \mathrm{L}=\mathrm{F}_{\text {plug }} \Delta \mathrm{L} \lambda+\mathrm{P}_{\text {ring }} 2 \pi \mathrm{rL} \Delta \mathrm{r}
$$




$$
\lambda=\frac{\text { Strain energy of plug with ring }}{\text { Work on free plug }}
$$

therefore,

$$
P_{\text {ring }}=\frac{\left(F_{\text {total }}-F_{\text {plug }} \lambda\right) \Delta L}{2 \pi r l \Delta r}
$$

Based on Eq. (2) of thin wall theory, hoop stress $\sigma_{\theta}$ can be expressed as following,

$$
\sigma_{\theta}=\frac{P_{\text {ring }} r}{t}=\frac{\left(F_{\text {total }}-F_{\text {plug }} \lambda\right) \Delta L r}{2 \pi r l \Delta r t}=\frac{F_{\text {ring }} \Delta L}{2 \pi \Delta r t l}=\chi \frac{F_{\text {ring }}}{t l}
$$

where, $\chi$ is a scaling factor used to correlate the ring load $\mathrm{F}_{\text {ring }}$ into hoop stress $\sigma_{\theta}$

$$
\begin{aligned}
& \chi=\frac{1}{2 \pi} \frac{\Delta L}{\Delta r} \\
& \mathrm{~F}_{\text {ring }}=\mathrm{F}_{\text {total }}-\lambda \mathrm{F}_{\text {plug, }} \\
& \Delta \mathrm{L}---- \text { plug total compression extension, } \\
& \Delta \mathrm{r} \text {----ring total radial dilatation, } \\
& \text { t---- ring specimen thickness, } \\
& \text { l-----ring specimen length, }
\end{aligned}
$$

In FEA, at the end of the process, compression extension of the plug is $\Delta \mathrm{L}=0.08$ in.; in the meantime, the ring radial dilatation reaches $\Delta \mathrm{r}=0.0212 \mathrm{in.}$ By applying Eq. (9), the scaling $\chi$-factor is calculated as 0.6. The ring specimen has thickness of 0.022 in. with length of 0.17 in.. The ring load $F_{\text {ring }}$ in Fig. 41(b) is converted into hoop stress $\sigma_{\theta}$ using Eq. (8), as shown in Fig. 42.

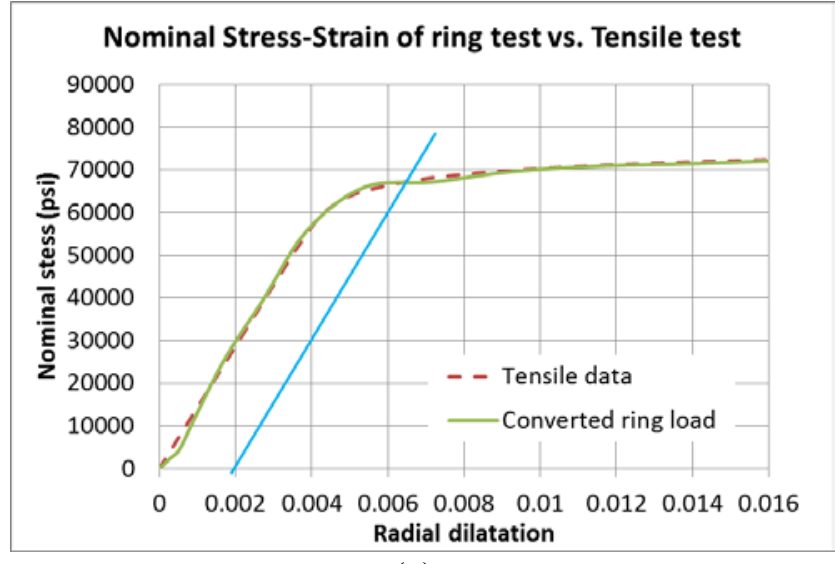

(a)

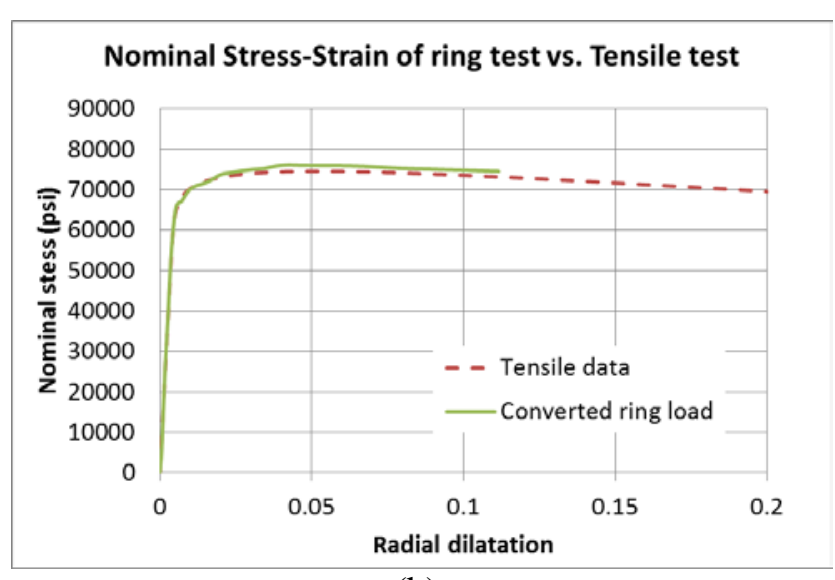

(b)

Fig. 42 Ring load-radial strain data from the ring test converted into material stress-strain curve for the modified expanded plug test design with wedge insertsexpanded plug wedge test.

The generated stress-strain curve agrees very well with that of tensile test data in both elastic and plastic regions. In the elastic region, the yield stress and Young's modulus match well with that of the tensile data; in plastic region, ultimate stress also matches well with that of the tensile data, and the converted ring load data also shows the strength hardening characteristics that was not observed from the current expanded plug test approach. Therefore, the material properties for the cladding material can be extracted correctly and effectively from the proposed expanded plug wedge test. 


\section{FUTURE WORK}

Further detailed study is needed on this subject. The proposed tasks for developing expanded plug wedge test are listed below.

Task 1: Select clad materials that have material characteristics similar to that of the fuel clad material of interest; selecting plug and insert materials, including the associated lubricant materials.

Task 2: Perform analytical and numerical simulation investigation on the proposed expanded plug wedge test:

(1) Parameter studies on the clad test sample dimensions, plug dimensions, and associated materials.

(2) Parameter studies on wedge insert geometry and dimensions, and on material selection, including the lubricant material for coating the wedge insert.

(3) System optimization and validation study on the proposed expanded plug wedge test.

Task 3: Perform modified expansion test setup and the counterpart tensile testing to validate the proposed expanded plug wedge test.

(1) Perform conventional tensile testing, including a ring test, to provide benchmark data for expanded plug wedge test simulation effort.

(2) Develop expanded plug wedge test samples, including clad, plug, and wedges; prepare expanded plug wedge test setup with the two end-pistons approach.

(3) Perform the expanded plug wedge test and analyze the test results.

Task 4: Initiate a standardization effort on the proposed expanded plug wedge test.

(1) Initiate dialogue with ANL, PNNL, and other national labs on forming a round robin testing group for testing the proposed new approach and for comparing it to conventional approaches for fuel clad mechanical properties evaluation.

(2) Communicate with the nuclear industry, such as fuel clad vendors and the nuclear utilities, on the proposed new approach for clad tensile properties evaluation.

Where possible, intertwine Tasks 2 and 3 until test results from the optimized design of the proposed expanded plug wedge test have been achieved. 


\section{SUMMARY}

Finite element models were established to simulate the current ORNL expanded plug method for mechanical property testing. A uniaxial compressive test and volumetric compressive test were performed. Test data were used in ABAQUS to calibrate coefficients of the hyperelastic material model of a polyurethane plug at room temperature, which were input as parameters in the FEM model. The expansion plug test system with unirradiated Zr-4 clad and polyurethane plug was evaluated using the established FEM model at room temperature.

FEA results show highly nonuniform stress and strain distribution in the unirradiated Zr-4clad at room temperature. Significant compressive stresses were observed in the resultant axial stress, which were induced by clad bending due to the clad bulging effect. The barreling effect caused very large localized shear stress in the clad wall, which might lead to shear failure of material at $45^{\circ}$. Compressive stress in cladding can further induce lateral expansion of the clad wall. The circumference strain estimated from the expansion plug test overestimates the strain deformation per the defined hoop stress due to the additional lateral expansion induced by the compressive stress. The compressive axial stress and shear stress in a plug-clad system cannot be ignored in the expansion plug testing.

The defined hoop stress obtained from the simplified scale factor approach significantly underestimates the true combined stress fields experienced by an expansion plug tested clad system, as indicated by this FEM analysis. The above combined effects of the overestimated circumference strain plus associated underestimated stress will result in nonconservative predictions both in strength and ductility of the tested clad, and the associated mechanical properties as well. FEA proves that stress fields in a clad material induced by the expansion plug test can be quite complicated and not really resemble pressurized cylinder clad stress-strain behaviors.

A ring expansion clad test at elevated temperature $350^{\circ} \mathrm{C}$ has also been evaluated in FEA. FEM simulations with unirradiated SRA Zircaloy-4 and irradiated SRA Zircaloy-4 clad and copper plug have been conducted. Similar deficiencies of the ring test using the current expanded plug method exist in the FEA results at elevated temperature.

To overcome the mentioned deficiencies associated with the current expansion plug test, systematic studies have been conducted. A modified expansion plug testing protocol has been developed based on detailed study using FEA. The first proposed design modification of the expanded plug test chose aluminum as the expansion plug material. A series of size effect studies for the axial length of clad and expansion plug have been performed. Per these recent systematic investigations, the optimized length has been determined based on producing a more uniform stress and strain distribution within the gage section. Lubrication is considered in the interface in order to reduce the interfacial shear stress and the consequence of axial compressive stress. FEM simulation results exhibit the apparent improvement in the stress and strain distribution at the gage section as well as the significant reduction in the axial stress induced by the barreling effect.

In addition to the first proposed modification, an expanded plug test with rigid wedges inserted between clad and plug has been developed. FEM simulation has proved that by using this approach, more improvement was gained regarding the uniform stress and strain distribution at the gage section than with the first proposed design modification that optimized the geometry alone. FEM results also show significantly less axial compressive stresses than that of the previous ORNL expansion plug method. A general procedure has been developed to determine the hoop stress $\sigma_{\theta}$ in the tested ring specimen, where a scaling factor called $\chi$-factor was developed to convert the ring load $P$ into hoop stress $\sigma_{\theta}$. The generated stress-strain curve agrees very well with that of the tensile test data in both the elastic and 
plastic regions. Therefore, the material properties for the cladding material can be extracted correctly from the proposed expanded plug wedge test. 


\section{REFERENCES}

1. http://en.wikipedia.org/wiki/Cylinder_stresses

2. http://www.codecogs.com/reference/engineering/materials/cylinders_and_spheres/thin_walled_cylind ers_and_spheres.php

3. http://www.efunda.com/formulae/solid_mechanics/mat_mechanics/pressure_vessel.cfm

4. Hendrich et al., United States Patent, Patent No. US 7140259 B2, Nov. 28, 2006.

5. http://www.matweb.com/ATI Wah Chang Zirconium Alloy Zircaloy-4

6. kal-Fredik Nilsson, Oliver Martin, Cesar Chenel-Ramos, Jose Mendes, “The segmented expanding cone-mandrel test revisited as material characterization and component test for fuel claddings," Nuclear Engineering and Design, 241, 445-458 (2011).

7. Sun-ki Kim, Je-Geon Bang, Dae-Ho Kim, Ik-Sung Lim, Yong-Sik Yang, Kun-Woo Song, Do-Sik Kim, "Hoop strength and ductility evaluation of irradiated fuel cladding," Nuclear Engineering and Design 239, 254-260 (2009).

8. Zhenyuan Hang and Xufeng Mi, "Behaviors of polyurethane filled double skin steel tubular members,” Applied Mechanics and Materials 94-96, 196-200 (2011).

9. http://www.efunda.com/materials/polymers/properties/polymer_datasheet.cfm

10. http://www.aksteel.com/pdf/markets_products/stainless/ferritic/430_Data_Sheet.pdf

11. Ridely Thrash et al., Southwire Company Overhead Conductor Manual, Second Edition, Southwire Company, Carrolton, Georgia, 2007.

12. http://www.axelproducts.com/downloads/TestingForHyperelastic.pdf

13. Abaqus Analysis User's Manual (6.10).

14. R. A. Jaramillo, W. R. Hendrich, N. H. Packan, Tensile Hoop Behavior of Irradiated Zircaloy-4 Nuclear Fuel Cladding, ORNL/TM-2006/163, Oak Ridge National Laboratory, December 2006.

15. IAEA Nuclear Energy Series, No. NF-T-2.1.

16. M. C. Billone, The Mechanical Properties Expertise Group Update on Round Robin Test Results, Argon National Laboratory Report, February 2002.

17. J.-A. J. Wang, H. Wang, T. Tan, H. Jiang, T. Cox, Y. Yan, Progress Letter Report on U-Frame Test Setup and Bending Fatigue Test for Vibration Integrity Study (Out-of-Cell Fatigue Testing Development - Task 2.2), ORNL/TM-2011/531, January 2012.

18. J. Gilbert Kaufman, Properties of Aluminum Alloys: Tensile, Creep, and Fatigue Data at High and Low Temperatures, The Aluminum Association, Inc. and ASM International ${ }^{\circledR}$, Washington, DC and Material Park, Ohio, September 2002. 
19. R. L. Brockenbrough and B. G. Johnston, “USS Steel Design Manual, Jan. 1981,” as published in Structural Alloys Handbook 3, 5 (1994).

20. http://www.roymech.co.uk/Useful_Tables/Tribology/co_of_frict.htm 